\title{
High-resolution Gamma Spectroscopy Measurements of Pressurized Water Reactor Spent Nuclear Fuel Rods
}

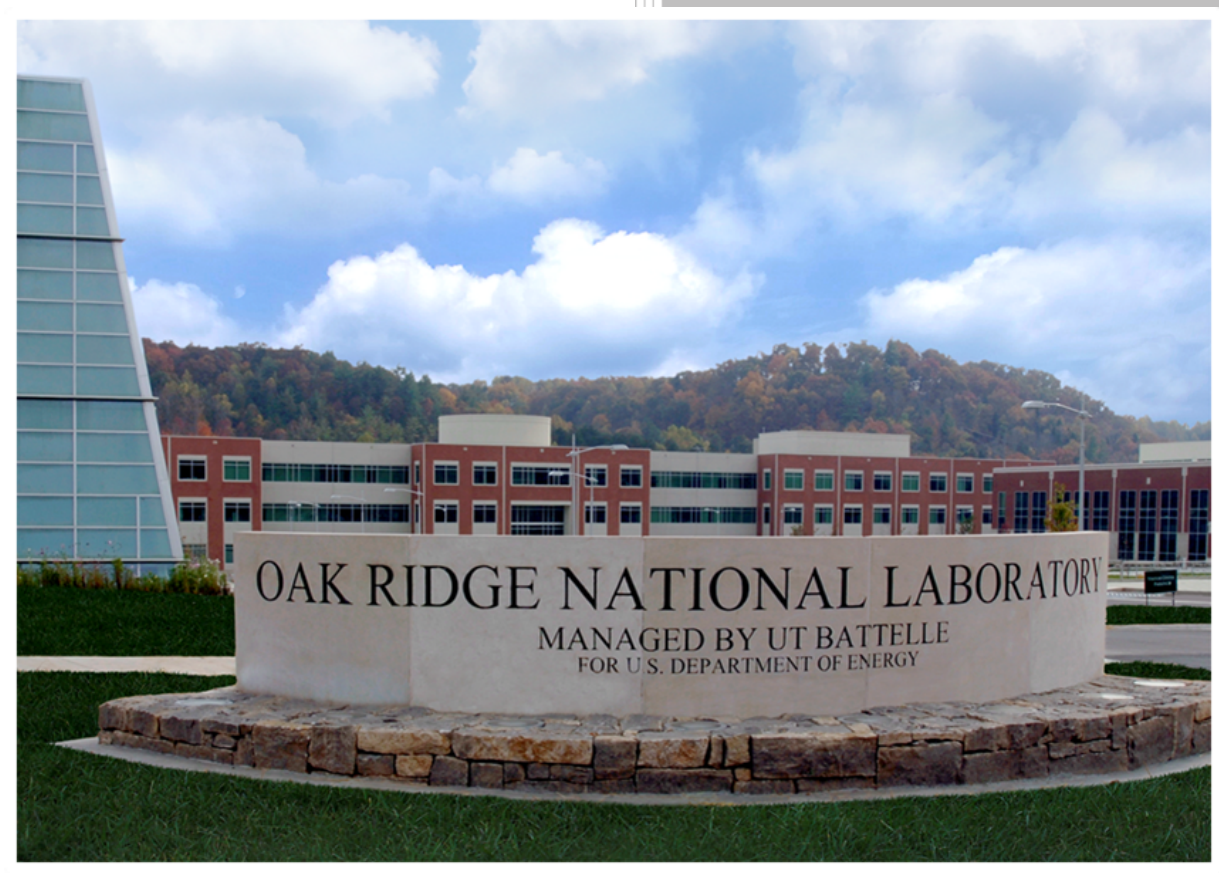

Susan Kane Smith Stephen Croft Andrew Nicholson Greg Nutter January 2018

Approved for public release. Distribution is unlimited. 


\title{
DOCUMENT AVAILABILITY
}

Reports produced after January 1, 1996, are generally available free via US Department of Energy (DOE) SciTech Connect.

Website http://www.osti.gov/scitech/

Reports produced before January 1, 1996, may be purchased by members of the public from the following source:

\author{
National Technical Information Service \\ 5285 Port Royal Road \\ Springfield, VA 22161 \\ Telephone 703-605-6000 (1-800-553-6847) \\ TDD 703-487-4639 \\ Fax 703-605-6900 \\ E-mail info@ntis.gov \\ Website http://classic.ntis.gov/
}

Reports are available to DOE employees, DOE contractors, Energy Technology Data Exchange representatives, and International Nuclear Information System representatives from the following source:

Office of Scientific and Technical Information

PO Box 62

Oak Ridge, TN 37831

Telephone 865-576-8401

Fax 865-576-5728

E-mail reports@osti.gov

Website http://www.osti.gov/contact.html

This report was prepared as an account of work sponsored by an agency of the United States Government. Neither the United States Government nor any agency thereof, nor any of their employees, makes any warranty, express or implied, or assumes any legal liability or responsibility for the accuracy, completeness, or usefulness of any information, apparatus, product, or process disclosed, or represents that its use would not infringe privately owned rights. Reference herein to any specific commercial product, process, or service by trade name, trademark, manufacturer, or otherwise, does not necessarily constitute or imply its endorsement, recommendation, or favoring by the United States Government or any agency thereof. The views and opinions of authors expressed herein do not necessarily state or reflect those of the United States Government or any agency thereof. 
Nuclear Security and Isotope Technology Division

\title{
MEASUREMENT OF PRESSURIZED WATER REACTOR
} SPENT NUCLEAR FUEL RODS BY HIGH-RESOLUTION GAMMA SPECTROSCOPY FOR BURNUP CODE VERIFICATION

\author{
Susan Kane Smith \\ Andrew Nicholson \\ Stephen Croft \\ Greg Nutter
}

Date Published: January 2018

Prepared by

OAK RIDGE NATIONAL LABORATORY

Oak Ridge, TN 37831-6283

managed by

UT-BATTELLE, LLC

for the

US DEPARTMENT OF ENERGY

under contract DE-AC05-00OR22725 



\section{CONTENTS}

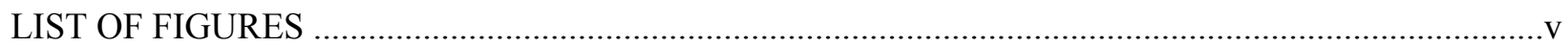

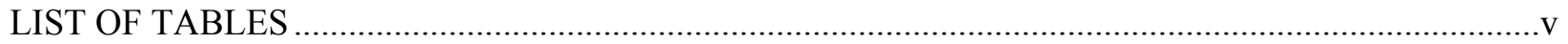

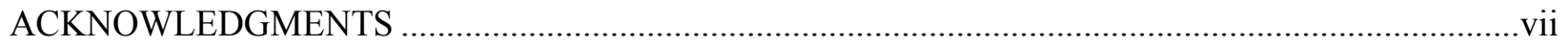

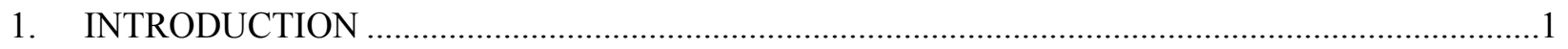

1.1 DETAILS OF SCANNED SPENT NUCLEAR FUEL RODS ........................................

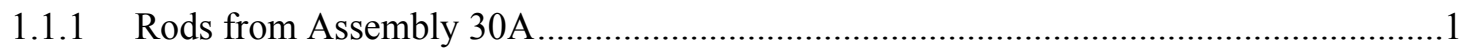

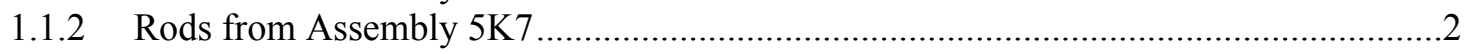

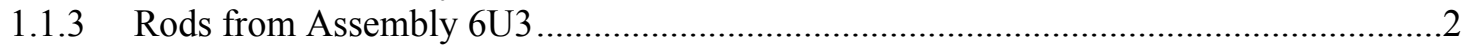

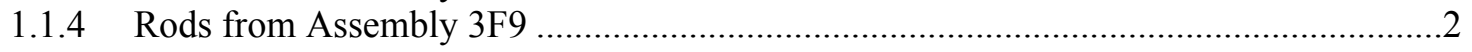

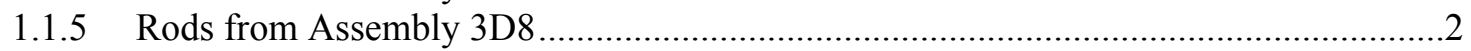

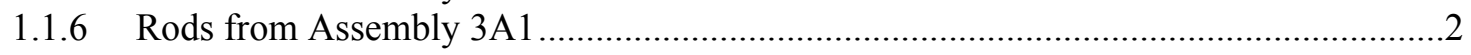

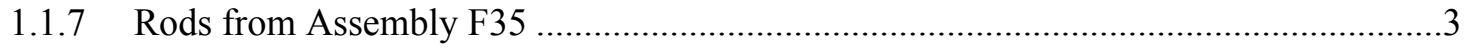

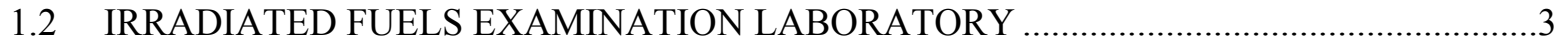

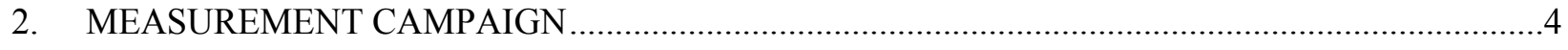

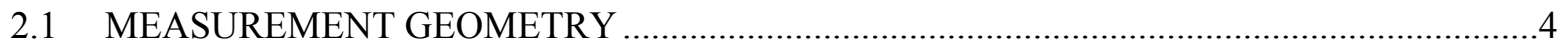

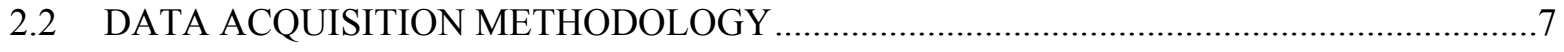

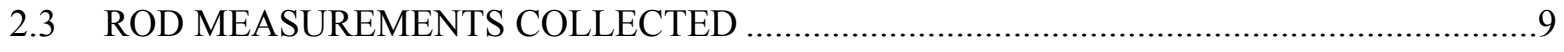

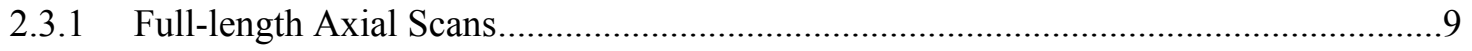

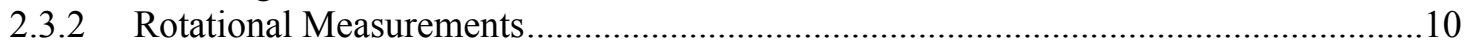

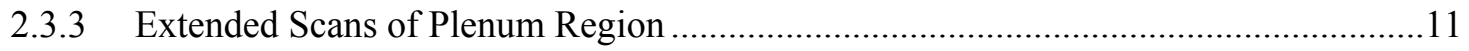

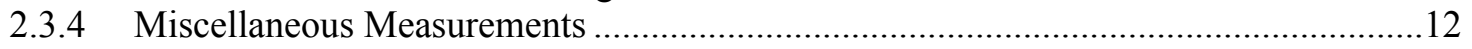

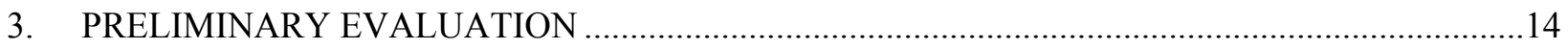

3.1 ATTENUATOR EVALUATION ON CONTINUM AND BACKSCATTER

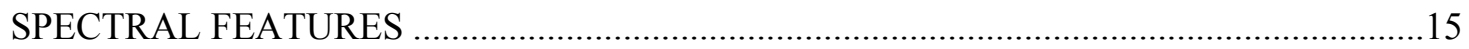

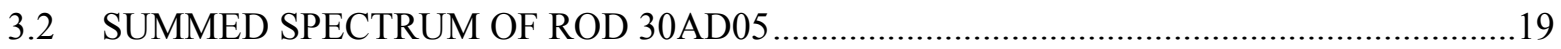

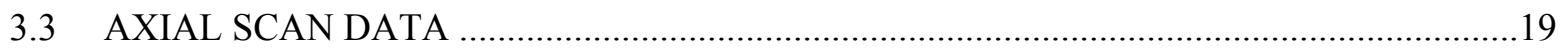

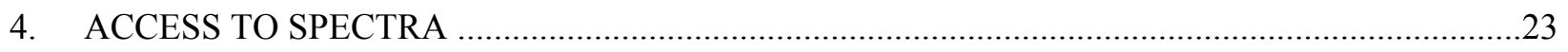

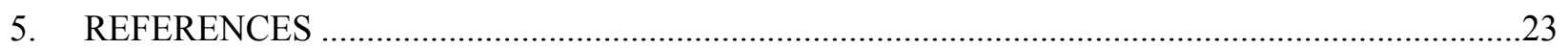





\section{LIST OF FIGURES}

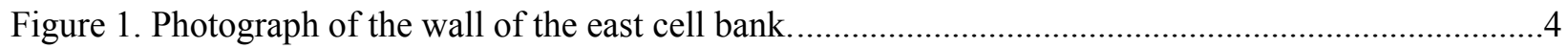

Figure 2. Photograph of the stainless-steel collimator with sliding wedge aperture. ................................5

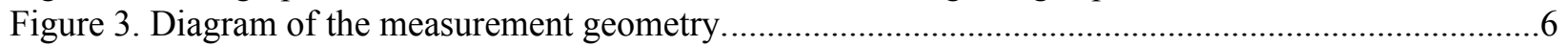

Figure 4. Photograph of the HPGe detector during spectroscopy measurements.....................................6

Figure 5. Screenshot of the spectrum acquisition software user interface..............................................

Figure 6. Photograph of ADEPT mechanism rotated 30 degrees. .....................................................11

Figure 7. Photographs of the detector oriented at a 15-degree angle (left) and 45-degree angle

(right) from the collimator axis

Figure 8. Comparison of gamma spectrum collected with a detector orientation of 0 degrees and

90 degrees.

Figure 9. Spectrum of rod 6U3P16 without attenuators present. ....................................................15

Figure 10. Change in the count rate of the backscatter ROI as a function of attenuation..........................17

Figure 11. Change in the count rate of the ${ }^{137} \mathrm{Cs} 662 \mathrm{keV}$ ROI as a function of attenuation......................18

Figure 12. Change in the count rate of the ${ }^{154} \mathrm{Eu} 1,275 \mathrm{keV}$ peak as a function of attenuation...................18

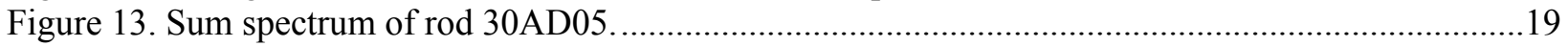

Figure 14. Axial scan of rod 30AD05 using the gross peak counts from the $661.6 \mathrm{keV}$ peak of ${ }^{137} \mathrm{Cs}$

Figure 15. Axial scan of rod 3D8B02 using the gross peak counts from the $661.6 \mathrm{keV}$ peak of ${ }^{137} \mathrm{Cs}$

Figure 16. Illustration of the axial scan data divided into sections.........................................................22

Figure 17. Net count rates of the $662 \mathrm{keV}$ peak of ${ }^{137} \mathrm{Cs}$ (left) and the $1,274 \mathrm{keV}$ peak of ${ }^{154} \mathrm{Eu}$

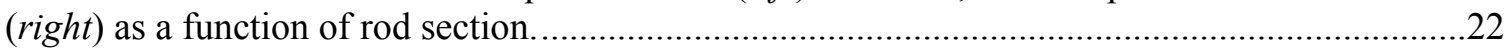

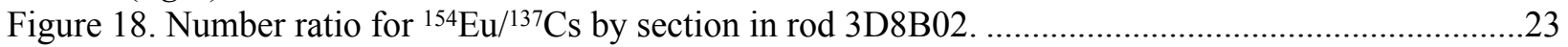

\section{LIST OF TABLES}

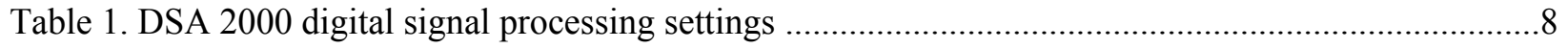

Table 2. Description of acquisition software data fields and relation to spectral acquisition........................8

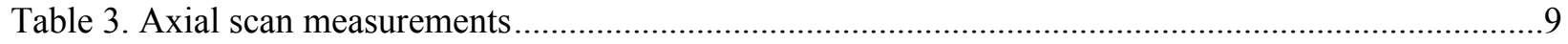

Table 4. Series of rotational measurements during the second measurement campaign ............................11

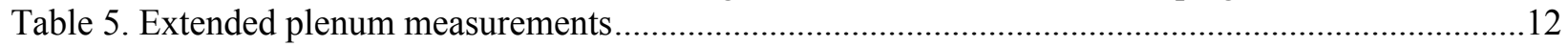

Table 6. Attenuators used during attenuator study measurements .......................................................13

Table 7. Rod position and reported deadtimes for measurements with and without live time

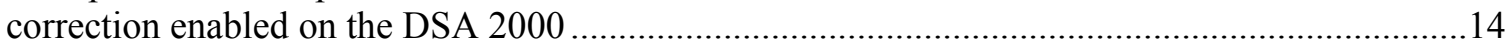

Table 8. Comparison of background and foreground count rates ...........................................................16

Table 9. Reduction in count rate due to the addition of $\mathrm{Cu}, \mathrm{Sn}$, and $\mathrm{Pb}$ shielding in various

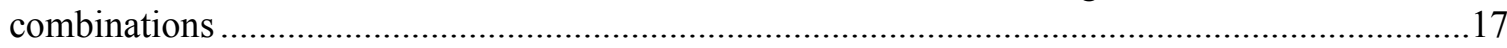




\section{ACKNOWLEDGMENTS}

We gratefully acknowledge the support and generosity of the International Nuclear Safeguards Technology Program, part of the Department of Energy's National Nuclear Security Agency, Office of Nonproliferation and Arms Control.

We would like to thank Bruce Bevard and Rose Montgomery for allowing us time in the schedule of the Post-irradiation High Burnup Demonstration Project Sister Rods to perform these gamma spectroscopy measurements. The Sister Rods project is sponsored by the Used Fuel Disposition Campaign of the Fuel Cycle Research and Development program in the Office of Nuclear Energy, US Department of Energy with UT-Battelle LLC.

Lastly, we would like to thank the personnel at the Irradiation Fuels Examination Laboratory for their work in moving the rods for our measurements and coordinating their movement. The support of Bob Morris was critical to the execution of the measurements as he modified software according to our needs, escorted us during our access to the laboratory, and often filled our detector with liquid nitrogen. 



\section{INTRODUCTION}

International nuclear safeguards use nondestructive assay techniques to verify declared characteristics of spent nuclear fuel (SNF) assemblies. The declared characteristics usually include the initial enrichment, assembly average burnup, and irradiation history. The primary nondestructive assay tool used by the International Atomic Energy Agency has been the fork detector irradiated fuel measurement system, which uses gross gamma and neutron correlations; however, there have been several research publications within the last decade on the use of high-resolution gamma spectroscopy for the determination of SNF characteristics. References [1]-[6] are published journal articles on this subject from 2006-2016.

This report describes measurements of 25 individual SNF rods using high-resolution gamma spectroscopy. Details of the measurement geometry, measurement settings, and rod characteristics are documented. These spectra are intended for the validation of simulation codes that calculate SNF inventory and source term characteristics. The spectrum archive is available to evaluate future spectrum analysis methods. The archive contains full axial scan spectra of each SNF rod. This allows more detailed comparison between simulation and nondestructive analysis than is possible on assemblies.

\subsection{DETAILS OF SCANNED SPENT NUCLEAR FUEL RODS ${ }^{1}$}

Through a collaboration of the Department of Energy's Office of Nuclear Energy, Dominion Energy, Westinghouse, and AREVA, 25 SNF rods were extracted from several SNF assemblies that were irradiated at the North Anna Power Station. The rods were shipped to Oak Ridge National Laboratory in 2016. These rods have well-known characteristics and all are considered high burnup with rod average burnups greater than $45 \mathrm{GWd} / \mathrm{MTU}$. The rods have an overall length of approximately 3,890 $\mathrm{mm}$ with a preirradiated minimal diameter of $9.5 \mathrm{~mm}$ [11]. All 25 rods will undergo nondestructive examination and destructive examination to determine the effects of irradiation and extended storage on the structural integrity of the cladding.

Additionally, 32 high-burnup fuel assemblies (having a total of 8,448 fuel rods) have been placed in dry storage and will remain there for 10 years. The 25 rods currently undergoing examination at ORNL are "sisters" to those in the storage cask, meaning that the fuel rods in storage have similar characteristics to those currently under examination because they have been extracted from assemblies with the same design and similar operating histories or from the same fuel assemblies. After the 10-year storage period, rods from the stored assemblies will be subjected to the same examinations performed on the sister rods.

This section provides a general description of each set of rods from the Post Irradiation Examination Plan for High-Burnup Demonstration Project Sister Rods [7], [8]. Some additional information comes from an updated draft of this same document [9].

\subsubsection{Rods from Assembly 30A}

Assembly 30A had a discharge assembly average burnup of $52.0 \mathrm{GWd} / \mathrm{MTU}$ and was discharged in 2010 . At the time of measurement, the cooling time was approximately 6 years. The assembly was a $17 \times 17$ fuel rod configuration of Advanced Mark-BW fuel. The rods were manufactured with M5 cladding and an initial enrichment of $4.55 \mathrm{wt} \%{ }^{235} \mathrm{U}$. The upper plenum length of these rods is about $182.2 \mathrm{~mm}$ on average [11]. There is no lower plenum.

Five sister rods were removed from the assembly and are available for measurement: 30AD05, 30AE14, 30AG09, 30AK09, and 30AP02.

\footnotetext{
${ }^{1}$ The information in this section is provided by and sometimes paraphrased from References [7], [8], and [9].
} 


\subsubsection{Rods from Assembly $5 \mathrm{~K} 7$}

Assembly 5K7 had a discharge assembly average burnup of $53.3 \mathrm{GWd} / \mathrm{MTU}$ and was discharged in 2008 . At the time of measurement, the cooling time was approximately 8 years. The assembly was a $17 \times 17$ fuel rod configuration of Advanced Mark-BW fuel. The rods were manufactured with M5 cladding and an initial enrichment of $4.55 \mathrm{wt} \%{ }^{235} \mathrm{U}$. The upper plenum length of these rods is $180.8 \mathrm{~mm}$ on average [11]. There is no lower plenum.

Four sister rods were removed from the assembly and are available for measurement: 5K7C05, 5K $7 \mathrm{~K} 09$, 5K7O14, and 5K7P02.

\subsubsection{Rods from Assembly 6U3}

Assembly $6 \mathrm{U} 3$ had a discharge assembly average burnup of $52.7 \mathrm{GWd} / \mathrm{MTU}$ and was discharged in 2006 . At the time of measurement, the cooling time was approximately 10 years. The assembly is a Westinghouse North Anna Improved Fuel assembly with ZIRLO cladding and an initial enrichment of $4.45 \mathrm{wt} \%{ }^{235} \mathrm{U}$. The upper plenum length of these rods is $178.7 \mathrm{~mm}$ on average [11]. There is no lower plenum.

Seven sister rods were removed from the assembly and are available for measurement: 6U3I07, 6U3K09, 6U3L08, 6U3M03, 6U3M09, 6U3O05, and 6U3P16.

\subsubsection{Rods from Assembly 3F9}

Assembly 3F9 had a discharge assembly average burnup of $52.3 \mathrm{GWd} / \mathrm{MTU}$ and was discharged in 2003 . At the time of measurement, the cooling time was approximately 13 years. The assembly is a Westinghouse North Anna Improved Fuel assembly with ZIRLO cladding and an initial enrichment of $4.25 \mathrm{wt} \%{ }^{235} \mathrm{U}$. The upper plenum length of these rods is $176.7 \mathrm{~mm}$ on average [11]. There is no lower plenum.

Three sister rods were removed from the assembly and are available for measurement: 3F9D07, 3F9N05, and 3F9P02. Rod 3F9D07 is calculated to have a rod burnup equivalent to the assembly average.

\subsubsection{Rods from Assembly 3D8}

Assembly 3D8 had a discharge assembly average burnup of 55.0 GWd/MTU and was discharged in 1999 . At the time of measurement, the cooling time was approximately 17 years. The assembly is a Westinghouse North Anna Improved Fuel assembly with ZIRLO cladding and an initial enrichment of $4.2 \mathrm{wt} \%{ }^{235} \mathrm{U}$. The upper plenum length of these rods is $174.5 \mathrm{~mm}$ on average [11]. There is no lower plenum.

Two sister rods were removed from the assembly and are available for measurement: 3D8B02 and 3D8E14. These rods represent the calculated lowest and highest burnup fuel rods in the assembly, respectively.

\subsubsection{Rods from Assembly 3A1}

Assembly 3A1 had a discharge assembly average burnup of $50 \mathrm{GWd} / \mathrm{MTU}$ and was discharged in 1994 . At the time of measurement, the cooling time was approximately 22 years. The assembly is a Westinghouse North Anna Improved Fuel assembly with low-tin Zircaloy-4 cladding and an initial enrichment of $4.0 \mathrm{wt} \%{ }^{235} \mathrm{U}$. The upper plenum length of these rods is $191.5 \mathrm{~mm}$ on average [11]. 
Two sister rods were removed from the assembly and are available for measurement: 3A1B16 and $3 \mathrm{~A} 1 \mathrm{~F} 05$. These rods represent the calculated lowest and highest burnup fuel rods in the assembly, respectively.

\subsubsection{Rods from Assembly F35}

Assembly F35 had a discharge assembly average burnup of $58 \mathrm{GWd} / \mathrm{MTU}$, but the cooling time has not been publicly documented. The assembly is a Westinghouse Low Parasitic fuel assembly design with Zircaloy-4 cladding and an initial enrichment of $3.59 \mathrm{wt} \%{ }^{235} \mathrm{U}$. The upper plenum length of these rods is $175.0 \mathrm{~mm}$ on average [11]. There is no upper plenum length.

Two sister rods were removed from the assembly and are available for measurement: F35K13 and F35P17.

\subsection{IRRADIATED FUELS EXAMINATION LABORATORY}

The sister rods are stored and examined in the Irradiated Fuels Examination Laboratory, Building 3525, at Oak Ridge National Laboratory. The first floor of the two-story building houses the primary high-level hot cell complex, consisting of three hot cell banks arranged in the shape of a "U." The shielded hot cell complex is constructed of $914.4 \mathrm{~mm}$ thick high-density baryte concrete and divided into three separate cell banks: the north cell, east cell, and west cell [11]. The sister rods are stored in the east cell. A penetration in the concrete wall allows gamma spectroscopy measurements of the fuel rods without contaminating the detectors (Figure 1). 


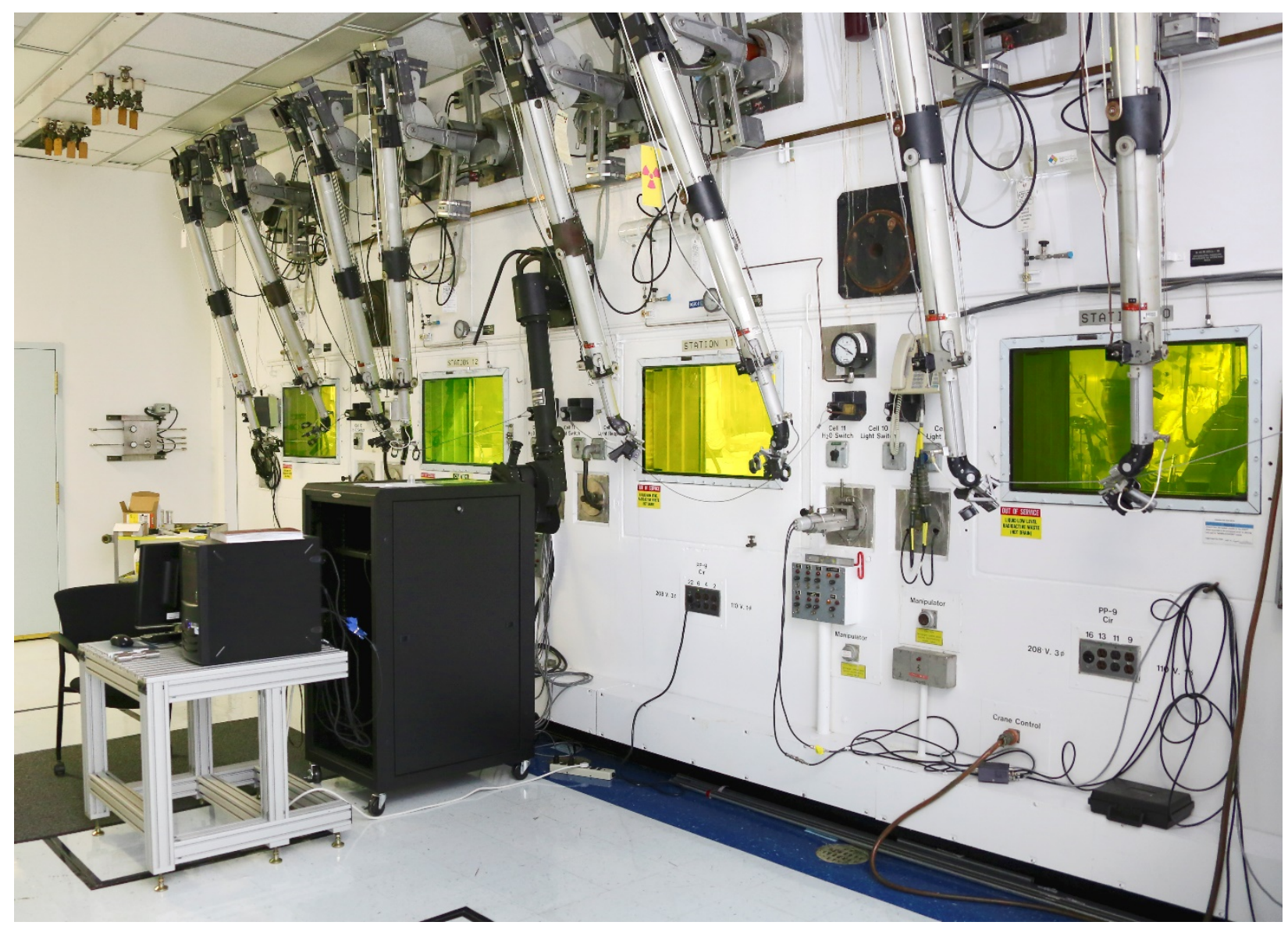

Figure 1. Photograph of the wall of the east cell bank. The two windows on the right-hand side of the photograph surround the port where the high-resolution gamma spectroscopy measurements were performed. A small NaI(Tl) detector can be seen mounted at the exit of the collimator.

\section{MEASUREMENT CAMPAIGN}

By coordinating with the Sister Rods project, we were allowed a total of 8.5 weeks of measurement time to perform full axial scans of all 25 individual SNF rods with a high-purity germanium (HPGe) gamma detector. Two measurement campaigns were performed: the first was conducted in January and February, and the second was in August and September 2017.

The measurement time was restricted by availability of the hot cell operators; consequently, only two rods could be scanned per day. The daytime measurement was completed between roughly 8:00 a.m. and 3:00 p.m., and the overnight measurement was completed between 4:00 p.m. and 6:00 a.m. Scans could not be performed over the weekends. The time was used to take long background measurements of the hot cell with and without a "dummy" rod. This section describes the measurement geometry and data acquisition methodology for the measurements.

\subsection{MEASUREMENT GEOMETRY}

Specialized equipment, the Advanced Diagnostics and Evaluation Platform (ADEPT), was designed and built in 2006-2007 for the measurement of individual fuel rods and then placed inside the east cell. 
"Runways" extending the length of a fuel rod contain roller assemblies to support the rod and allow their movement through a central measurement station. A stainless-steel collimator was designed to allow gamma spectroscopy measurements. It extends through the hot cell's concrete wall to within $254 \mathrm{~mm}$ of the SNF rod inside the hot cell. The end of the collimator inside the hot cell is covered with a sapphire window to prevent the entry of radioactive particles. The sliding wedge aperture can be opened from approximately $1 \mathrm{~mm}$ to $6 \mathrm{~mm}$. Figure 2 shows the collimator and its aperture [12].

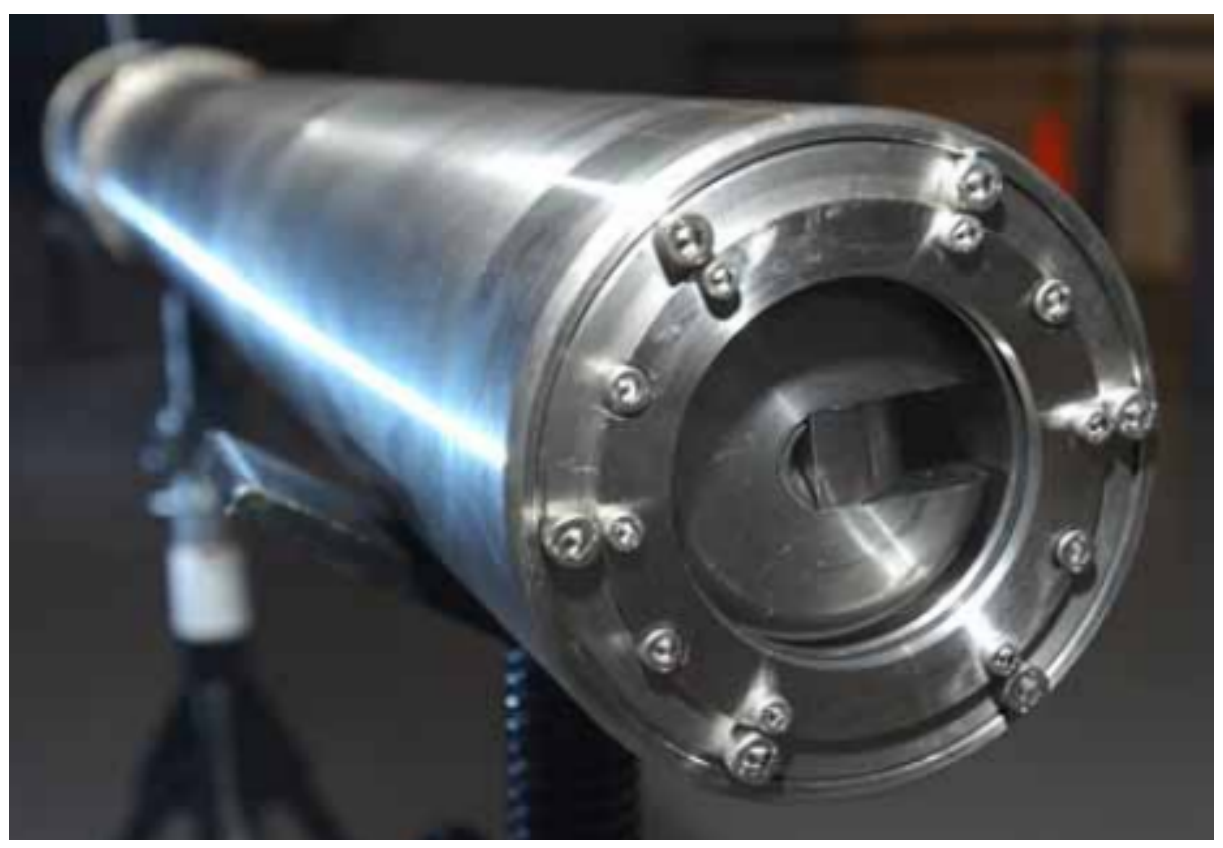

Figure 2. Photograph of the stainless-steel collimator with sliding wedge aperture. [12]

The detector chosen for the measurements is a large p-type semi-planar HPGe manufactured by Canberra Industries (model BE3820). A $50.8 \mathrm{~mm}$ thick modular lead shielding and positioning assembly was used to shield potential room background and improve measurement reproducibility as seen in Figure 4. 


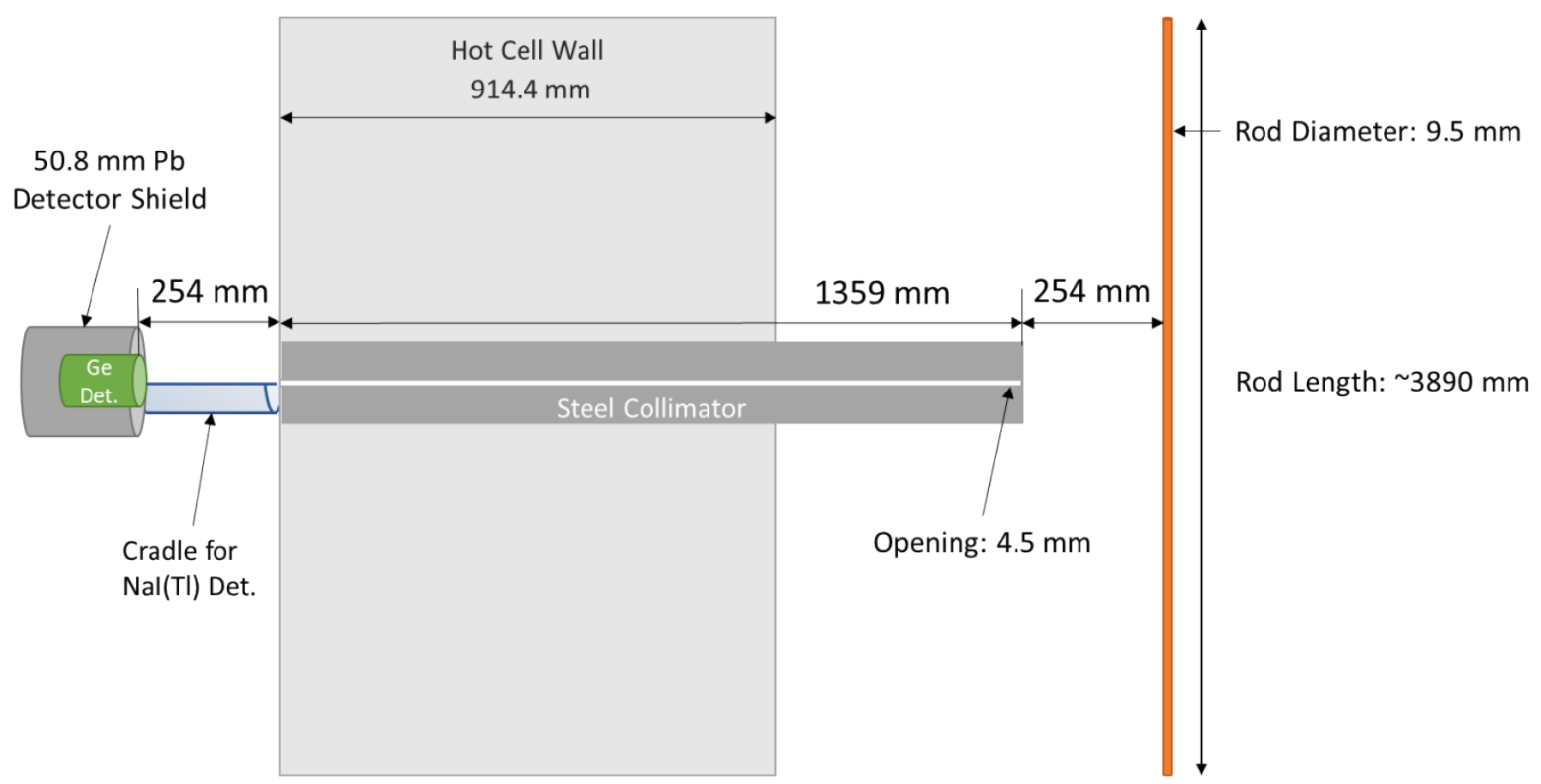

Figure 3. Diagram of the measurement geometry. The steel collimator extends through and beyond the hot cell concrete wall to within $254 \mathrm{~mm}$ of the fuel rod. A cradle was built onto the end of the collimator for the $\mathrm{NaI}(\mathrm{Tl})$ detector measurements and could not be removed for the HPGe detector measurements.

Figure 4 illustrates the measurement geometry. The collimator includes a cradle for gamma spectroscopy measurements with a sodium iodide $(\mathrm{NaI}(\mathrm{Tl}))$ detector, which cannot be removed. Because the HPGe detector is larger in diameter than the $\mathrm{NaI}(\mathrm{Tl})$ detector it could not fit in the cradle, and the detector could be placed no closer than $254 \mathrm{~mm}$ from the face of the collimator. The collimator aperture was opened to approximately $4.5 \mathrm{~mm}$. The height is such that the full diameter of the rods is in the field of view. The collimator determines the count rate because the area of the HPGe detector is much larger than the aperture.

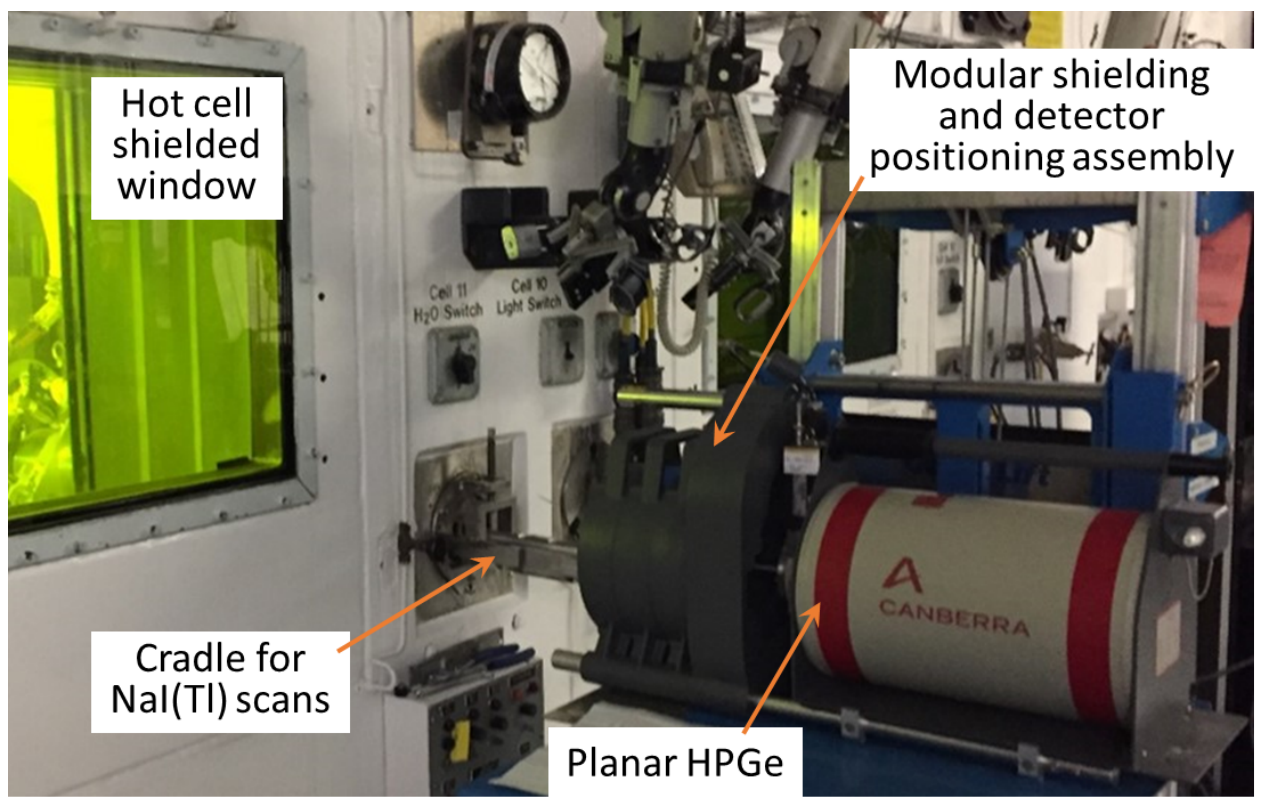

Figure 4. Photograph of the HPGe detector during spectroscopy measurements. The arrows indicate key features of the measurement geometry outside of the hot cell. 


\subsection{DATA ACQUISITION METHODOLOGY}

The Irradiated Fuels Examination Laboratory has a CANBERRA DSA 2000 multichannel analyzer and CANBERRA Genie 2000 software V3.2.1 to perform the data acquisition. The digital signal processing settings are listed below in Table 1. The laboratory also has a custom-designed software for ADEPT with a simple user interface that coordinates data acquisition through Genie 2000 software and the movement of the rod thru the mechanical controller, allowing discrete spectral acquisition at predefined locations along the rods. Figure 5 shows the simple user interface and Table 2 describes each of the fields.

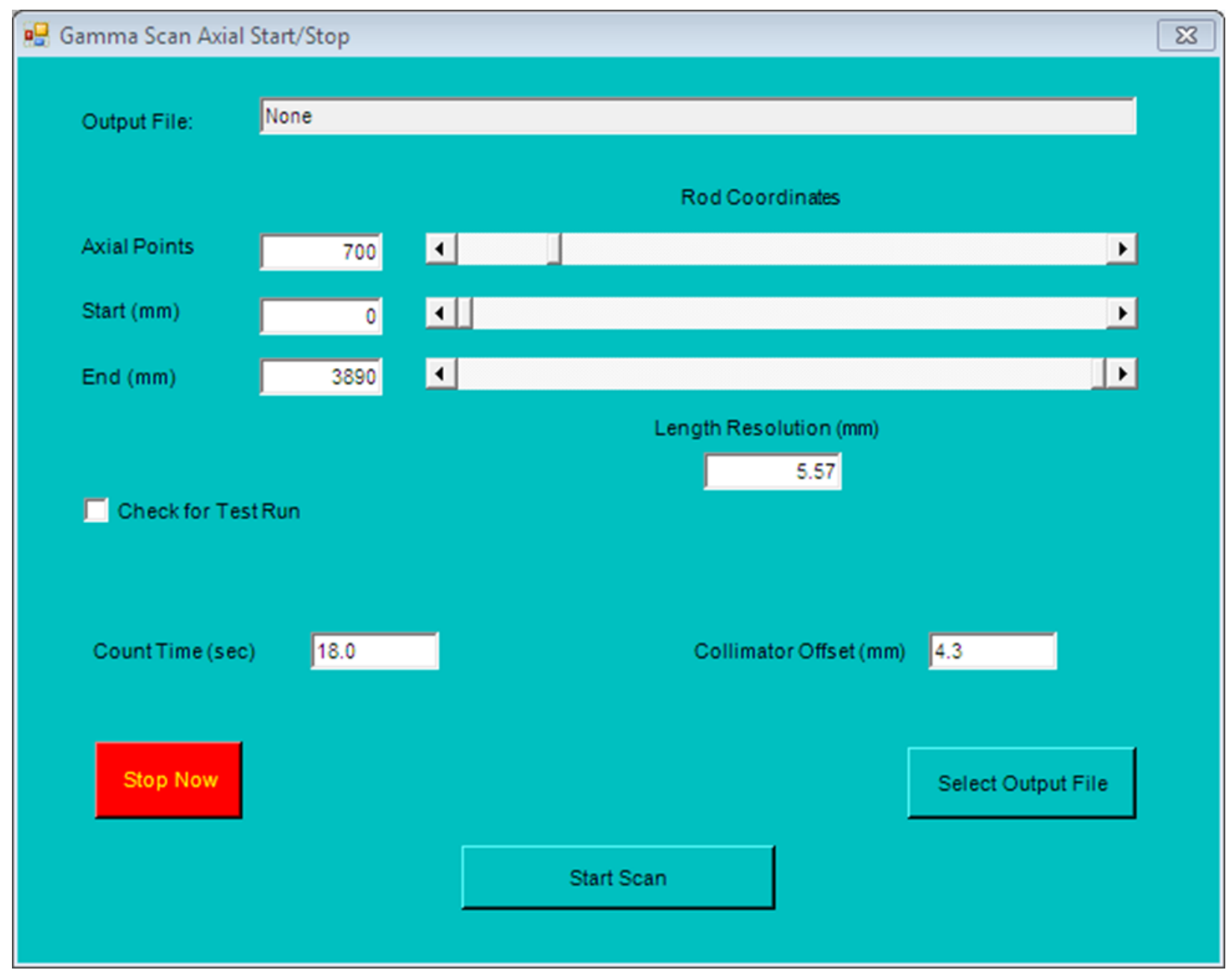

Figure 5. Screenshot of the spectrum acquisition software user interface. 
Table 1. DSA 2000 digital signal processing settings

\begin{tabular}{lc}
\hline Setting description & Value \\
\hline High voltage & $4000 \mathrm{~V}$ \\
Inhibit signal & $5 \mathrm{~V}$ \\
Output polarity & Positive \\
Conversion gain & 8192 \\
Coarse gain & 15.000 \\
Fine gain & 1.1093 \\
S-fine gain & 0.015048 \\
Amplifier gain & 16.865 \\
Lower-level discriminator & 0.10376 \\
Fast discriminator mode & Auto \\
Live time correction & On \\
Pile-up rejection guard & 1.1000 \\
Rise time & $5.6 \mu \mathrm{s}$ \\
Flat top & $0.8 \mu \mathrm{s}$ \\
Base-line restore mode & Auto \\
Pole zero & 3147 \\
\hline
\end{tabular}

Table 2. Description of acquisition software data fields and relation to spectral acquisition

\begin{tabular}{ll}
\hline \multicolumn{1}{c}{ Field } & \multicolumn{1}{c}{ Description } \\
\hline Output file & Prefix name for saved data files \\
Axial points & Number of positions along the length of the rod to perform the measurement \\
Start $(\mathrm{mm})$ & Starting position \\
End $(\mathrm{mm})$ & Ending position \\
Length resolution $(\mathrm{mm})$ & $\begin{array}{l}\text { Length of fuel rod seen by detector through the collimator opening automatically } \\
\text { calculated based on the collimator offset field }\end{array}$ \\
Count time (s) & Live time of the data acquisition \\
Collimator offset & Physical size of the collimator aperture \\
Stop now & Button to cancel the scan \\
Select output file & Button to select a preexisting data file to append additional scan results \\
Start scan & Start movement of the rod and data acquisition \\
\hline
\end{tabular}

The parameter values entered in Figure 5 are those typically used for the HPGe measurements taken during the day; 700 spectra were collected in discrete steps of approximately $5.56 \mathrm{~mm}$ along the entire length of the fuel rod $(3,890 \mathrm{~mm})$. The collimator offset was $4.3 \mathrm{~mm}$. In general, an $18 \mathrm{~s}$ live time was used for scans performed during the workday, and a $50 \mathrm{~s}$ live time was used for scans performed overnight. These settings were selected as a tradeoff between count time and deadtime to ensure two rods could be measured each calendar day. We worked in terms of live time, which means that elapsed time varied somewhat with incoming count rate. 
Like the hardware, the software was originally developed for the axial scanning of the fuel rod with a $\mathrm{NaI}(\mathrm{Tl})$ detector. The software extracted only gross counts from three regions of interest from each measurement and recorded the counts in a text file. The individual spectrum from each measurement point was not saved. The program was modified to save each spectrum collected using a user-defined prefix, the date, and the position of the rod during that measurement file naming scheme. For example, a spectrum collected of rod F35P17 performed on February 1, 2017 at position $123.7 \mathrm{~mm}$ is saved with the filename F35P17-2017020201_P+0123d7.cnf.

\subsection{ROD MEASUREMENTS COLLECTED}

The following sections provide details on each set of measurements performed during the measurement campaigns. Two campaigns were undertaken: the first was from January 9 to February 3, 2017, and the second was from August 30 to September 19, 2017.

\subsubsection{Full-length Axial Scans}

Scans were performed in approximately $5.6 \mathrm{~mm}$ increments along the entire length of each rod (Table 3). The information includes the date of acquisition, start and stop position, number of spectra collected, and live time of each spectrum acquisition. Unless otherwise noted, the detector was positioned so that the detector axis matched the collimator axis.

Table 3. Axial scan measurements

\begin{tabular}{lcccccc}
\hline \multicolumn{1}{c}{ Rod } & Date & $\begin{array}{c}\text { Live time } \\
\text { (s) }\end{array}$ & $\begin{array}{c}\text { No. of } \\
\text { spectra }\end{array}$ & $\begin{array}{c}\text { Start position } \\
(\mathbf{m m})\end{array}$ & $\begin{array}{c}\text { Stop position } \\
(\mathbf{m m})\end{array}$ & $\begin{array}{c}\text { Step size } \\
(\mathbf{m m})\end{array}$ \\
\hline Assembly 30A & & & & & & \\
\hline 30AD05 & $1 / 10 / 2017$ & 50 & 700 & 0 & 3,886 & 5.56 \\
30AE14 & $1 / 11 / 2017$ & 50 & 700 & 0 & 3,881 & 5.55 \\
30AE14 & $1 / 24 / 2017$ & 50 & 700 & 0 & 3,882 & 5.55 \\
30AG09 & $1 / 10 / 2017$ & 18 & 700 & 0 & 3,882 & 5.55 \\
30AK09 & $8 / 30 / 2017$ & 50 & 700 & 0 & 3,882 & 5.55 \\
30AP02 & $1 / 24 / 2017$ & 18 & 700 & 0 & 3,882 & 5.55 \\
\hline Assembly 5K7 & & & & & & \\
\hline 5K7C05 & $1 / 19 / 2017$ & 18 & 700 & 0 & 3,884 & 5.56 \\
5K7C05 & $9 / 5 / 2017$ & 50 & 700 & 0 & 3,884 & 5.56 \\
5K7K09 & $1 / 23 / 2017$ & 50 & 700 & 0 & 3,884 & 5.56 \\
5K7O14 & $1 / 31 / 2017$ & 50 & 700 & 0 & 3,884 & 5.56 \\
5K7P02 & $1 / 31 / 2017$ & 50 & 700 & 0 & 3,882 & 5.55 \\
\hline Assembly 6U3 & & & & & & \\
\hline 6U3I07 & $1 / 18 / 2017$ & 18 & 700 & 0 & 3,889 & 5.56 \\
6U3K09 & $1 / 30 / 2017$ & 18 & 700 & 0 & 3,890 & 5.57 \\
6U3L08 & $1 / 30 / 2017$ & 50 & 700 & 0 & 3,890 & 5.57 \\
6U3M03 & $1 / 18 / 2017$ & 18 & 700 & 0 & 3,889 & 5.56 \\
6U3M09 & $1 / 23 / 2017$ & 18 & 700 & 0 & 3,890 & 5.57 \\
6U3M09 & $8 / 31 / 2017$ & 50 & 700 & 0 & 3,890 & 5.57 \\
6U3O05 & $1 / 20 / 2017$ & 18 & 700 & 0 & 3,890 & 5.57 \\
6U3P16 & $1 / 12 / 2017$ & 50 & 700 & 0 & 3,890 & 5.57 \\
6U3P16 ${ }^{a}$ & $9 / 6 / 2017$ & 50 & 50 & 100 & 3,850 & 76.53 \\
\hline & & & & & &
\end{tabular}


Table 3. (continued)

\begin{tabular}{lcccccc}
\hline \multicolumn{1}{c}{ Rod } & Date & $\begin{array}{c}\text { Live time } \\
(\mathbf{s})\end{array}$ & $\begin{array}{c}\text { No. of } \\
\text { spectra }\end{array}$ & $\begin{array}{c}\text { Start position } \\
(\mathbf{m m})\end{array}$ & $\begin{array}{c}\text { Stop position } \\
(\mathbf{m m})\end{array}$ & $\begin{array}{c}\text { Step size } \\
(\mathbf{m m})\end{array}$ \\
\hline Assembly 3F9 & & & & & & \\
\hline 3F9D07 & $1 / 19 / 2017$ & 50 & 700 & 0 & 3,890 & 5.57 \\
3F9N05 & $1 / 9 / 2017$ & 25 & 700 & 0 & 3,892 & 5.57 \\
3F9P02 & $1 / 25 / 2017$ & 18 & 700 & 0 & 3,891 & 5.57 \\
\hline Assembly 3D8 & & & & & & \\
\hline 3D8B02 & $1 / 26 / 2017$ & 50 & 700 & 0 & 3,890 & 5.57 \\
3D8E14 & $1 / 17 / 2017$ & 50 & 700 & 0 & 3,894 & 5.57 \\
3D8E14 & $9 / 6 / 2017$ & 50 & 700 & 0 & 3,894 & 5.57 \\
\hline Assembly 3A1 & & & & & & \\
\hline 3A1B16 & $1 / 25 / 2017$ & 50 & 700 & 0 & 3,892 & 5.57 \\
3A1B16 & $9 / 1 / 2017$ & 20 & 792 & 0 & 3,563 & 4.50 \\
3A1F05 & $1 / 18 / 2017$ & 50 & 700 & 0 & 3,894 & 5.57 \\
\hline Assembly F35 & & & & & & \\
\hline F35K13 & $2 / 2 / 2017$ & 50 & 700 & 0 & 3,887 & 5.56 \\
F35P17 & $2 / 2 / 2017$ & 18 & 700 & 0 & 3,890 & 5.57 \\
F35P17 & $9 / 7 / 2017$ & 50 & 700 & 0 & 3,890 & 5.57 \\
\hline
\end{tabular}

${ }^{a}$ Axial scans were performed with detector axis at a 90-degree angle from the collimator axis.

\subsubsection{Rotational Measurements}

After the initial campaign, the question of radial symmetry was raised among the researchers. The ADEPT machine was designed to grip the rod to control its movement, and the machine is able to rotate an assembly to present the rod at different azimuthal angles to the collimator. Figure 6 shows a photograph of the ADEPT assembly at an angle of 30 degrees. With this ability, additional spectra were collected at serval azimuthal angles at a set axial position. The measurements are cataloged in Table 4. Unless otherwise noted, the detector was positioned so that the detector axis matched the collimator axis. 


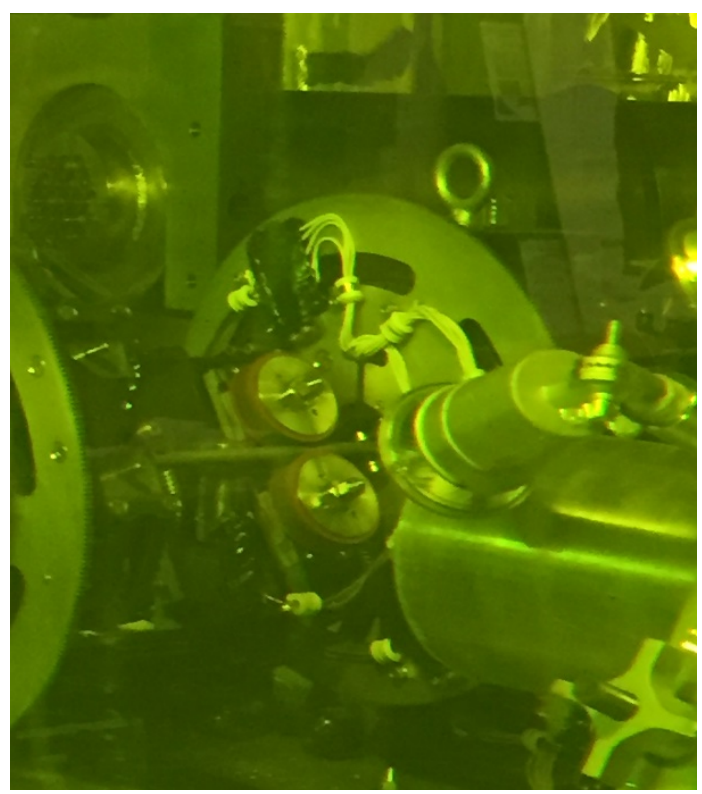

Figure 6. Photograph of ADEPT mechanism rotated 30 degrees. The mechanism does not block the collimator's view of the rod. The collimator is the cylinder on the right-hand side of the photograph.

Table 4. Series of rotational measurements during the second measurement campaign

\begin{tabular}{lccccc}
\hline \multicolumn{1}{c}{ Rod } & Date & $\begin{array}{c}\text { Position } \\
(\mathbf{m m})\end{array}$ & $\begin{array}{c}\text { Time } \\
\text { (s) }\end{array}$ & $\begin{array}{c}\text { No. of } \\
\text { spectra }\end{array}$ & $\begin{array}{c}\text { Step size } \\
\text { (deg) }\end{array}$ \\
\hline 6U3P16 & $9 / 6 / 2017$ & 2,565 & $600($ Real) & 12 & 30 \\
3D8E14 & $9 / 7 / 2017$ & $1,399.5$ & $300($ Live) & 12 & 30 \\
3D8E14a & $9 / 7 / 2017$ & $1,416.3$ & $300($ Live) & 12 & 30 \\
3F9P02 & $9 / 12 / 2017$ & $1,313.7$ & $300($ Live) & 12 & 30 \\
3F9P02 & $9 / 13 / 2017$ & $2,143.1$ & $300($ Live) & 12 & 30 \\
30AD05 & $9 / 13 / 2017$ & 3,143 & $300($ Live) & 12 & 30 \\
3A1F05 & $9 / 14 / 2017$ & 600 & 300 (Live) & 12 & 30 \\
3A1F05 & $9 / 14 / 2017$ & 650 & 300 (Live) & 12 & 30 \\
30AE14 & $9 / 15 / 2017$ & 1,850 & 300 (Live) & 12 & 30 \\
3F9D07 & $9 / 18 / 2017$ & 1,395 & 300 (Live) & 4 & 90.00 \\
F35P17 & $9 / 19 / 2017$ & 2,233 & 300 (Live) & 8 & 45.00 \\
F35P17 & $9 / 19 / 2017$ & $2,238.4$ & 300 (Live) & 8 & 45.00 \\
\hline
\end{tabular}

${ }^{a}$ Axial scans were performed with detector axis at a 90-degree angle from the collimator axis.

\subsubsection{Extended Scans of Plenum Region}

During the second measurement campaign, extended measurements of the rod plenum regions were conducted. The intent was to determine if ${ }^{85} \mathrm{Kr}$ could be used as an additional fission product to calculate cooling time. Although ${ }^{85} \mathrm{Kr}$ has a 10.7 year half-life, its primary gamma ray at $\sim 514 \mathrm{keV}$ has only a $0.4 \%$ branching ratio [13]. To quantify the amount of ${ }^{85} \mathrm{Kr}$ present, strong statistics must be present in the spectrum; hence the long measurements collected over the plenum region. Table 5 describes the series of 
axial scans performed. Unless otherwise noted, the detector was positioned so that the detector axis matched the collimator axis.

Table 5. Extended plenum measurements

\begin{tabular}{ccccccc}
\hline Rod & Date & $\begin{array}{c}\text { Live time } \\
(\mathbf{s})\end{array}$ & $\begin{array}{c}\text { No. of } \\
\text { spectra }\end{array}$ & $\begin{array}{c}\text { Start position } \\
(\mathbf{m m})\end{array}$ & $\begin{array}{c}\text { Stop position } \\
(\mathbf{m m})\end{array}$ & $\begin{array}{c}\text { Step size } \\
(\mathbf{m m})\end{array}$ \\
\hline 30AD05 & $9 / 13 / 2017$ & 240 & 42 & 3,690 & 3,876 & 4.54 \\
30AE14 & $8 / 30 / 2017$ & 240 & 41 & 3,688 & 3,866 & 4.45 \\
30AG09 & $9 / 18 / 2017$ & 240 & 42 & 3,685 & 3,871 & 4.54 \\
5K7C05 & $9 / 5 / 2017$ & 240 & 41 & 3,694 & 3,872 & 4.45 \\
5K7O14 & $9 / 12 / 2017$ & 1,200 & 40 & 3,698 & 3,875 & 4.54 \\
6U3I07 & $9 / 19 / 2017$ & 240 & 39 & 3,701 & 3,875 & 4.58 \\
6U3K09 & $9 / 12 / 2017$ & 240 & 40 & 3,698 & 3,876 & 4.56 \\
6U3M09 & $8 / 31 / 2017$ & 240 & 41 & 3,694 & 3,872 & 4.45 \\
6U3O05 & $9 / 13 / 2017$ & 1,200 & 41 & 3,695 & 3,877 & 4.55 \\
3F9D07 & $9 / 18 / 2017$ & 1,200 & 39 & 3,706 & 3,878 & 4.53 \\
3F9N05 & $9 / 11 / 2017$ & 1,200 & 44 & 3,700 & 3,892 & 4.47 \\
3D8E14 & $9 / 14 / 2017$ & 1,200 & 31 & 3,706 & $3,842.2$ & 4.54 \\
3D8E14 & $9 / 15 / 2017$ & 1,200 & 11 & 3,838 & 3,883 & 4.50 \\
3A1B16 & $9 / 5 / 2017$ & 20 & 74 & 3,563 & 3,891 & 4.49 \\
3A1F05 & $9 / 14 / 2017$ & 240 & 43 & 3,693 & 3,884 & 4.55 \\
F35P17 $^{a}$ & $9 / 11 / 2017$ & 20 & 40 & 0 & 177 & 4.54 \\
\hline
\end{tabular}

${ }^{a}$ Axial scans were performed with detector axis at a 90-degree angle from the collimator axis.

${ }^{b}$ Scan was interrupted due to mandatory computer restart. It was continued the next day.

In addition to the axial scans, the plenum of rod 30AE14 was measured over a weekend, which is approximately 60 hours real time. The rod was positioned in front of the collimator at $3,719 \mathrm{~mm}$ from the bottom of the rod and the collimator aperture opened to $6.0 \mathrm{~mm}$.

\subsubsection{Miscellaneous Measurements}

\subsubsection{Attenuator Evaluation}

As will be discussed in the next chapter, an evaluation of the necessity of an attenuator was investigated due to the prominent Compton continuum and backscatter peak in all spectra collected. Rod 6U3P16 was used for the study and the position of the rod in front of the collimator fixed at $2,565 \mathrm{~mm}$. Live-time data acquisition was set to a period of 300 seconds. The following list describes the attenuators used for the measurement study. 
Table 6. Attenuators used during attenuator study measurements

\begin{tabular}{ccc}
\hline $\begin{array}{c}\text { Cu thickness } \\
(\mathbf{m m})\end{array}$ & $\begin{array}{c}\text { Sn thickness } \\
(\mathbf{m m})\end{array}$ & $\begin{array}{c}\text { Pb thickness } \\
(\mathbf{m m})\end{array}$ \\
\hline 0.0 & 0.0 & 0.0 \\
1.0 & 0.0 & 0.0 \\
1.0 & 0.5 & 0.0 \\
1.0 & 1.0 & 0.0 \\
1.0 & 1.5 & 0.0 \\
1.0 & 2.0 & 0.0 \\
1.0 & 2.5 & 0.0 \\
1.0 & 0.5 & 6.0 \\
\hline
\end{tabular}

\subsubsection{Detector Orientation}

Using rod $6 \mathrm{U} 3 \mathrm{P} 16$ at position $2,565 \mathrm{~mm}$, the detector orientation with respect to the centerline of the collimator was systematically changed. The goal of the measurements was to determine if the backscatter peak could be reduced by changing the detector volume presented to the gamma rays coming through the collimator. Measurements were performed with the detector axis at 0 degrees, 15 degrees, 30 degrees, 45 degrees, and 90 degrees from the collimator axis. The five measurements were acquired with a $300 \mathrm{~s}$ live time.
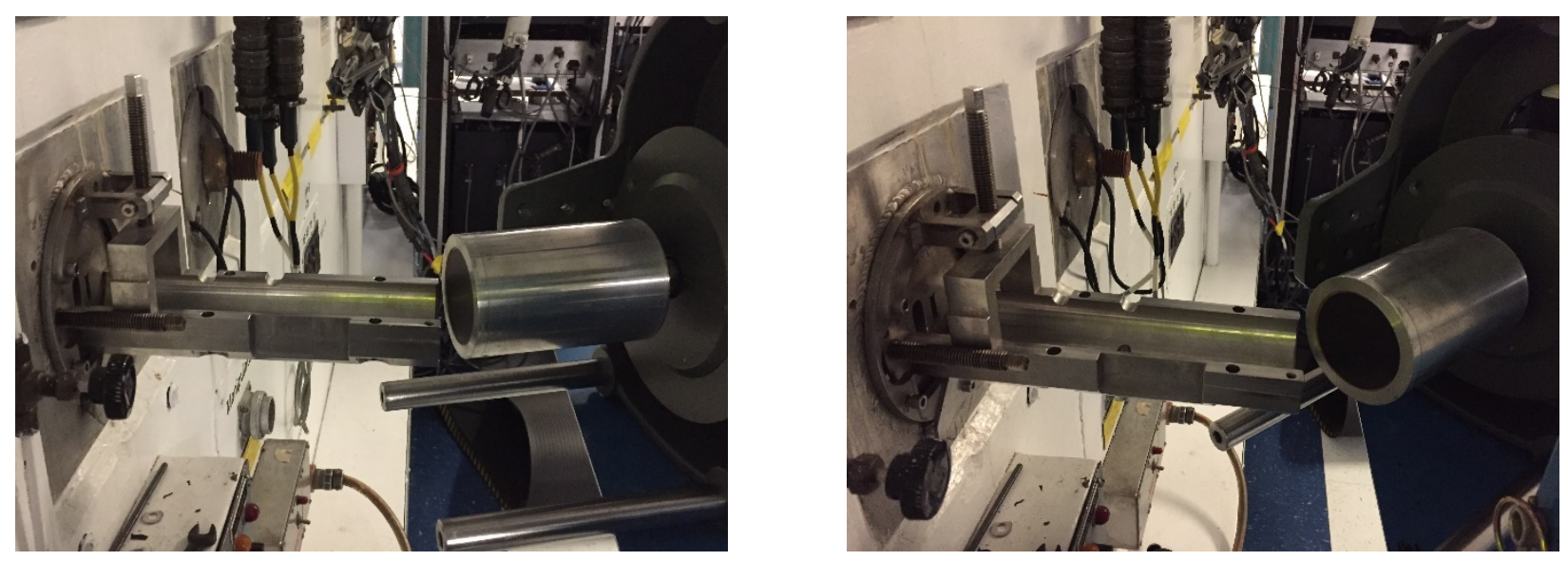

Figure 7. Photographs of the detector oriented at a 15-degree angle (left) and 45-degree angle (right) from the collimator axis.

By visually comparing the spectra, one can see how the backscatter feature and Compton edge become muted with increasing angle. Figure 8 shows a comparison of the spectrum acquired with a detector orientation at 0 degrees to the collimator axis (shown in black) and the detector oriented 90 degrees to the collimator axis (shown in blue). The latter is purposely offset to facilitate visual comparison of the region below $600 \mathrm{keV}$. 


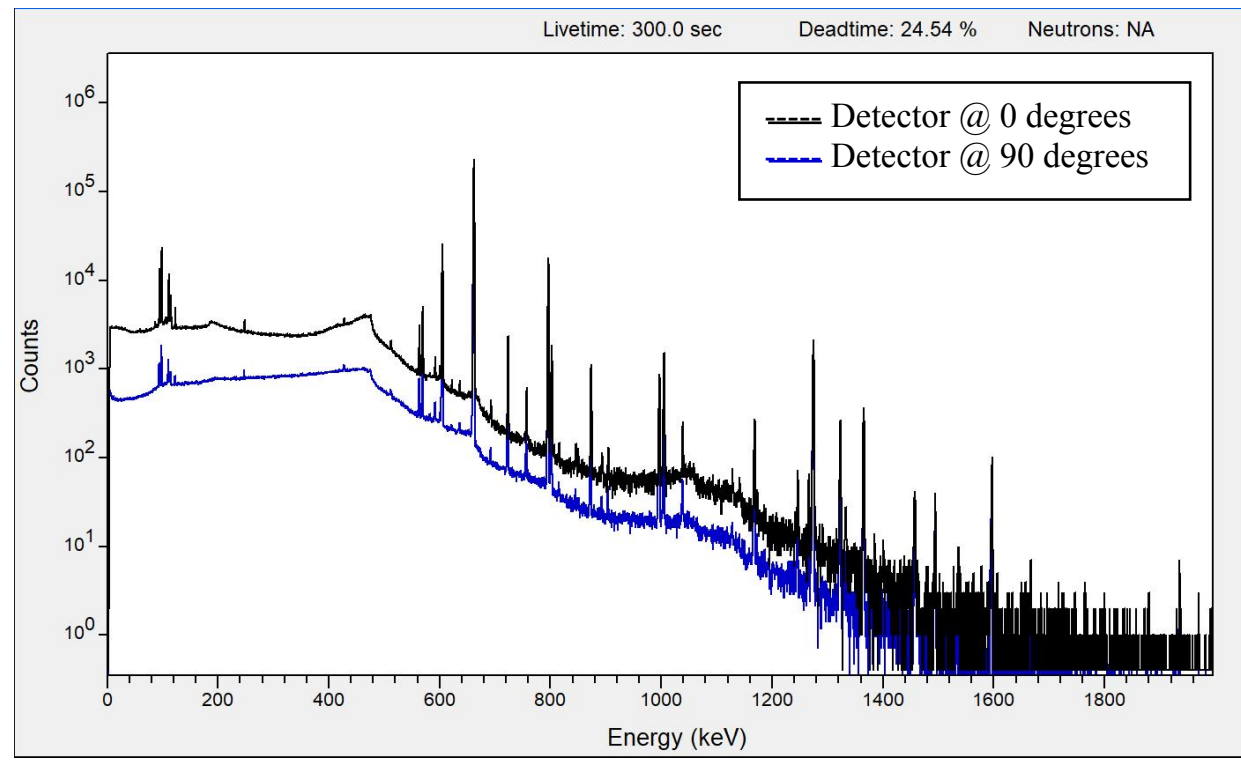

Figure 8. Comparison of gamma spectrum collected with a detector orientation of 0 degrees and 90 degrees. The spectrum acquired at 90 degrees is shown in blue and purposely offset to demonstrate the difference in features below $600 \mathrm{keV}$.

\subsubsection{Deadtime Correction Verification}

Several spectra were acquired using rod 6U3P16 to verify the live time correction performed by the DSA 2000 during acquisition. An ${ }^{241} \mathrm{Am}$ check source was placed underneath the detector to provide an independent reference peak that would be used for the verification. At four positions along the length of the rod, to verify the performance along a range of count rates, spectra were acquired for $400 \mathrm{~s}$ (real time) with the live time correction on and turned off. Analysis has not been performed on the data.

Table 7. Rod position and reported

deadtimes for measurements with and without live time correction enabled on the DSA 2000

\begin{tabular}{lcc}
\hline \multirow{2}{*}{ Position } & \multicolumn{2}{c}{ Reported deadtime } \\
\cline { 2 - 3 } & LTC On & LTC Off \\
\hline $225 \mathrm{~mm}$ & $23.7 \%$ & $14.7 \%$ \\
$2565 \mathrm{~mm}$ & $28.1 \%$ & $17.6 \%$ \\
$3600 \mathrm{~mm}$ & $17.0 \%$ & $10.2 \%$ \\
$3670 \mathrm{~mm}$ & $13.8 \%$ & $8.1 \%$ \\
\hline
\end{tabular}

\section{PRELIMINARY EVALUATION}

This section describes preliminary evaluation of the spectra; an evaluation of the usefulness of a detector attenuator, an example of a full rod summed spectrum, and the axial scan data for two SNF rods. 


\subsection{ATTENUATOR EVALUATION ON CONTINUM AND BACKSCATTER SPECTRAL FEATURES}

During initial measurements to optimize the settings, the prominent Compton continuum and backscatter peak indicated that we should investigate the use of an absorber to reduce these features. Figure 9 presents a measurement of rod $6 \mathrm{U} 3 \mathrm{P} 16$ at 2,565 mm for a live-time data acquisition period of $300 \mathrm{~s}$. The Compton edge is prominent at approximately $475 \mathrm{keV}$ and the backscatter peak interferes with the $186 \mathrm{keV}$ peak from ${ }^{235} \mathrm{U}$, spanning approximately $30 \mathrm{keV}$.

Using SNF rod 6U3P16, a series of measurements were performed: a $1 \mathrm{~mm}$ copper disc, several $0.5 \mathrm{~mm}$ tin discs, and a $6 \mathrm{~mm}$ lead disc mounted on the front face of the detector. Foreground and background spectra were acquired: foreground measurements for $300 \mathrm{~s}$ live time and background measurements for $3,600 \mathrm{~s}$ live time. All foreground measurements were taken within one shift, whereas background measurements were taken over several days. The detector was left in the same position for all measurements with the rod removed from the field of view for the background measurements. A baseline measurement was made with no absorbers. A $1 \mathrm{~mm}$ copper layer was added, and the measurement was repeated. Increasing thicknesses of tin were then added, and a measurement was made for each. The final foreground measurement included a lead absorber.

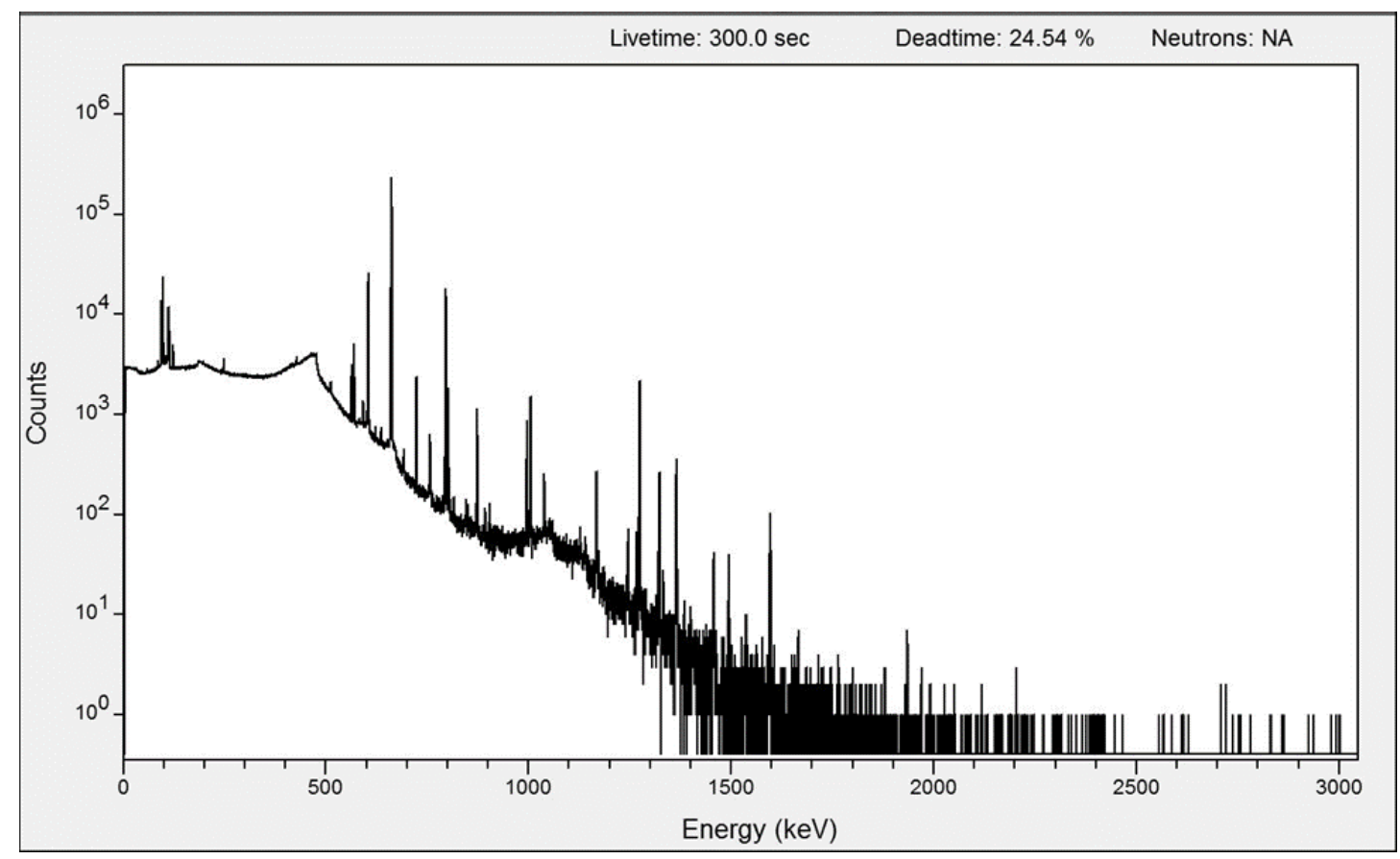

Figure 9. Spectrum of rod 6U3P16 without attenuators present. Fission product and activation nuclide peaks sit atop a large Compton continuum. A strong Compton Edge and backscatter peak can be seen below $500 \mathrm{keV}$.

The spectra were analyzed using PeakEasy software [12]. Regions of interest (ROI) were set at the energies listed in Table 8. An ROI was also set around the backscatter peak, approximately $190 \mathrm{keV}$. The software did not adequately correct for the background and Compton continuum portion of the lower energy peaks, up to $661.6 \mathrm{keV}$, so continuum ROIs were created for them and used to make the corrections. The continuum correction was made using Equation 1. The software satisfactorily corrected the higher energy peaks, those above $662 \mathrm{keV}$. 


$$
\begin{gathered}
C=G-\left(w_{1} B_{1}+w_{2} B_{2}\right) \\
w_{1}=\frac{n\left(x_{2}-x\right)}{n_{1}\left(x_{2}-x_{1}\right)}, w_{2}=\frac{n\left(x-x_{1}\right)}{n_{2}\left(x_{2}-x_{1}\right)} \\
\sigma(C)=\sqrt{C+w_{1}^{2} B_{1}+w_{2}^{2} B_{2}}
\end{gathered}
$$

Equation 1. Compton continuum correction for ROI analysis. [13]

In Equation 1, $C$ is the net count rate in the peak ROI, $G$ is the total count rate in the peak ROI, $B$ is the total count rate in the background ROI, $w$ is the ROI width weighting factors, $x$ is the average channel number in the ROI, $n$ is the number of channels in the ROI, and subscripts 1 and 2 refer to the lower- and upper-energy background ROIs. It is assumed that the weighting factors have no uncertainty as the limits of the ROIs are known and do not vary.

The data were then evaluated to determine if the addition of attenuating absorbers would remove enough Compton and scatter contribution from the hot cell and measurement conditions to usefully improve the signal-to-noise ratio and resolution of the lower energy gamma peaks. One of the background measurements was analyzed in the same manner as the foreground measurements. The background contribution was found to be negligible and no background subtractions were performed. A comparison of a typical background spectra and one of the foregrounds is shown in Table 8. The attenuation of the selected gamma rays was also compared as a function of absorber type and thickness.

Table 8. Comparison of background and foreground count rates

\begin{tabular}{cccc}
\hline $\begin{array}{c}\text { Gamma-ray peak } \\
(\mathbf{k e V})\end{array}$ & $\begin{array}{c}\text { Normalized background } \\
\text { total count rate } \\
(\mathbf{c p s})\end{array}$ & $\begin{array}{c}\text { Peak count rate with } \\
\mathbf{1} \mathbf{~ m m ~ C u}+\mathbf{~ 1 m m} \text { Sn } \\
(\mathbf{c p s})\end{array}$ & $\begin{array}{c}\text { Ratio of background to } \\
\text { foreground }\end{array}$ \\
\hline Scatter & 255.44 & $1,324.59$ & $19.28 \%$ \\
563.2 & 1.47 & 94.82 & $1.55 \%$ \\
569.3 & 1.28 & 118.33 & $1.08 \%$ \\
604.7 & 2.16 & 353.85 & $0.61 \%$ \\
661.6 & 2.09 & $2,997.93$ & $0.07 \%$ \\
795.8 & 0.78 & 251.26 & $0.31 \%$ \\
873.2 & 0.68 & 21.08 & $3.21 \%$ \\
996.3 & 0.5 & 17.83 & $2.80 \%$ \\
$1,004.8$ & 0.53 & 26.71 & $2.00 \%$ \\
$1,274.5$ & 0.52 & 36.47 & $1.43 \%$ \\
\hline
\end{tabular}

The addition of the absorbers obstructing the field of view of the detector yielded predictable attenuation of the gamma spectra from the hot cell. Addition of a lead absorber yielded the greatest reduction in peak area for all energies examined. The $563.2 \mathrm{keV}$ and higher energy peaks showed a somewhat linear decline in the net peak count rate as the tin absorber thickness increased. Table 9 with the accompanying charts in Figure 10, Figure 11, and Figure 12 show the attenuation of three selected peaks. The scatter peak showed much less sensitivity to the addition of attenuating absorbers (again, excepting lead). There was $10 \%$, or less, difference between the nonattenuated peak count rate and the peak count rates of the measurements using copper and tin absorbers. This illustrates that much of the backscatter contribution comes from the detector and detector shielding. Adding attenuation did not sufficiently improve the signal-to-noise ratio of the lower energy peaks to be justified. 
Table 9. Reduction in count rate due to the addition of $\mathrm{Cu}, \mathrm{Sn}$, and $\mathrm{Pb}$ shielding in various combinations

\begin{tabular}{|c|c|c|c|c|c|}
\hline \multirow{2}{*}{$\begin{array}{c}\text { Cu thickness } \\
(\mathrm{mm})\end{array}$} & \multirow{2}{*}{$\begin{array}{l}\text { Sn thickness } \\
(\mathbf{m m})\end{array}$} & \multirow{2}{*}{$\begin{array}{l}\text { Pb thickness } \\
(\mathrm{mm})\end{array}$} & \multicolumn{3}{|c|}{$\%$ Difference from unattenuated } \\
\hline & & & Scatter peak & $\begin{array}{c}137 \mathrm{Cs} \\
661.6 \mathrm{keV}\end{array}$ & $\begin{array}{c}{ }^{154} \mathrm{Eu} \\
1,274.5 \mathrm{keV}\end{array}$ \\
\hline 1.0 & 0.0 & 0.0 & $10.46 \%$ & $5.99 \%$ & $2.13 \%$ \\
\hline 1.0 & 0.5 & 0.0 & $6.37 \%$ & $8.24 \%$ & $3.12 \%$ \\
\hline 1.0 & 1.0 & 0.0 & $4.41 \%$ & $10.83 \%$ & $5.95 \%$ \\
\hline 1.0 & 1.5 & 0.0 & $9.11 \%$ & $13.63 \%$ & $7.14 \%$ \\
\hline 1.0 & 2.0 & 0.0 & $0.35 \%$ & $16.10 \%$ & $8.60 \%$ \\
\hline 1.0 & 2.5 & 0.0 & $0.53 \%$ & $18.57 \%$ & $10.94 \%$ \\
\hline 1.0 & 0.5 & 6.0 & $44.32 \%$ & $59.79 \%$ & $38.58 \%$ \\
\hline
\end{tabular}

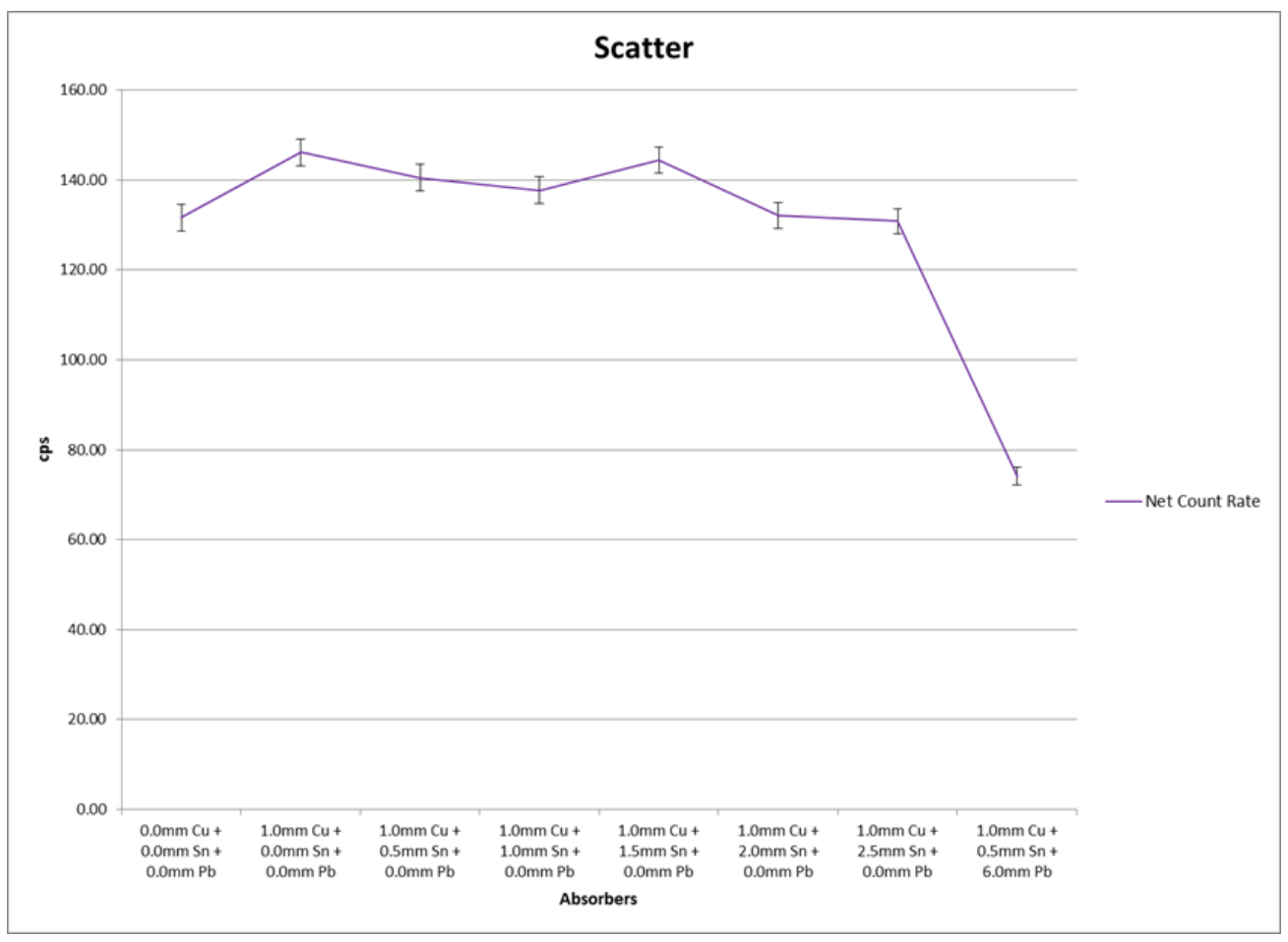

Figure 10. Change in the count rate of the backscatter ROI as a function of attenuation. 


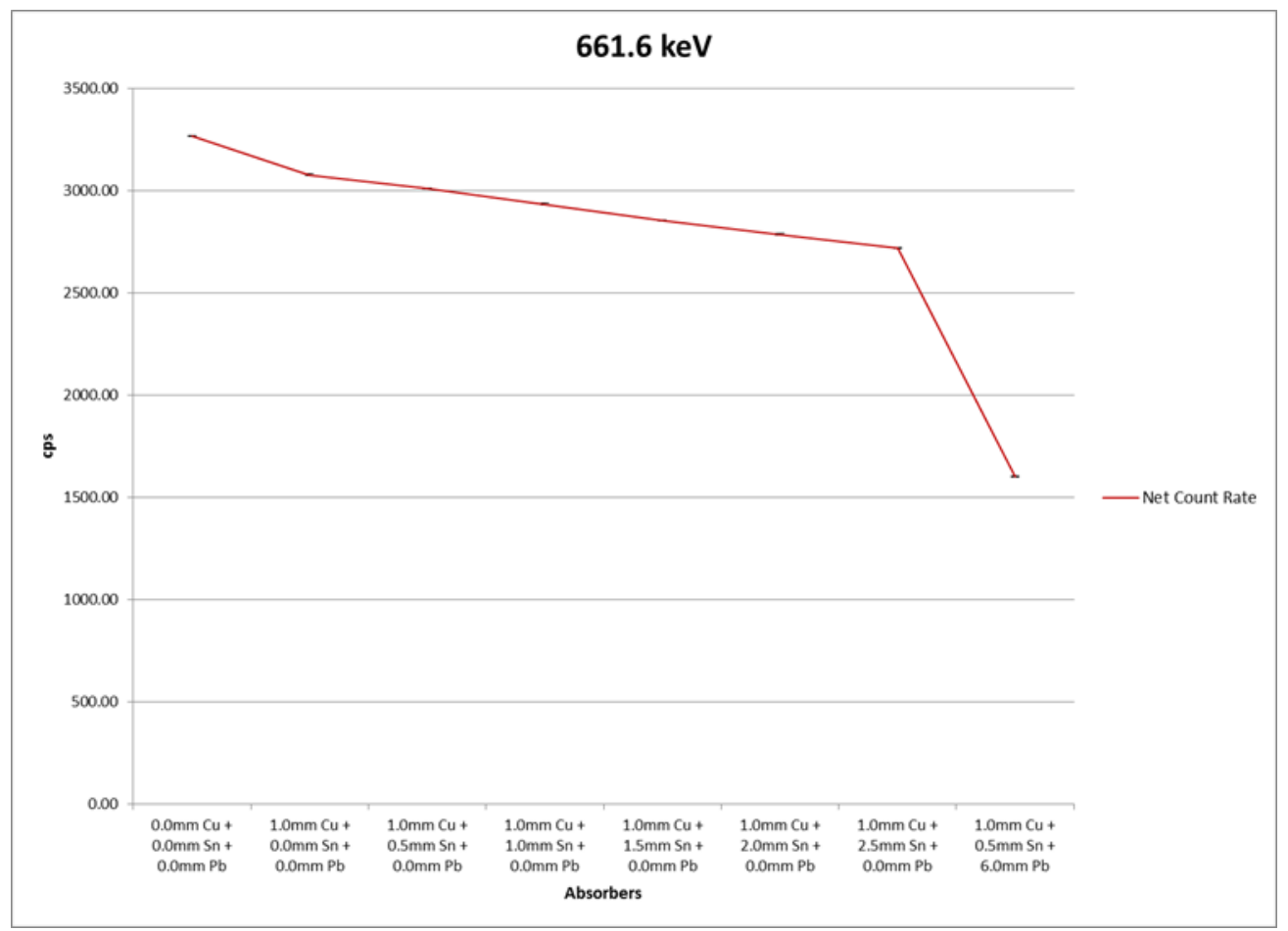

Figure 11. Change in the count rate of the ${ }^{137} \mathrm{Cs} 662 \mathrm{keV}$ ROI as a function of attenuation.

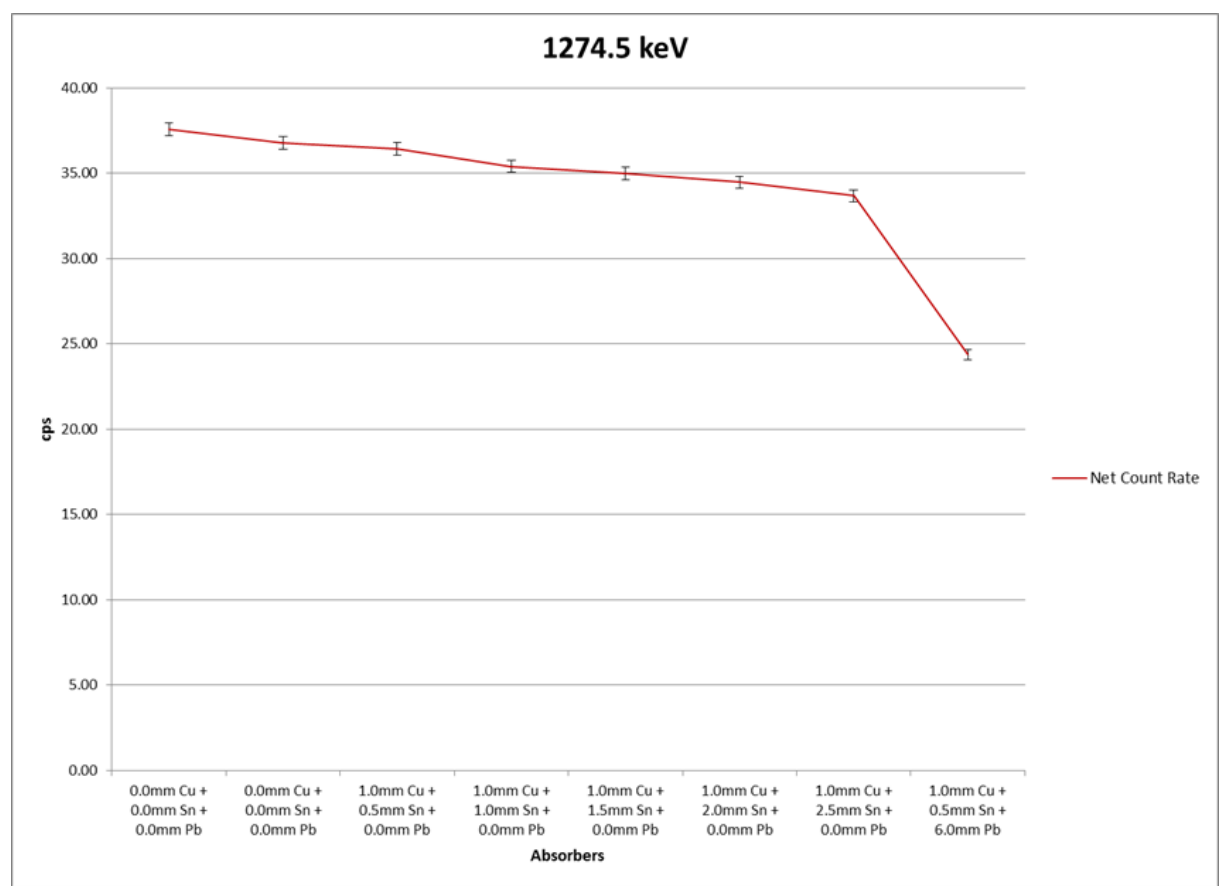

Figure 12. Change in the count rate of the ${ }^{154} \mathrm{Eu} 1,275 \mathrm{keV}$ peak as a function of attenuation.

Because of this evaluation, it was concluded that the backscatter peak may be the result of scattering off the detector cup. This was confirmed by performing measurements with the detector at an angle with 
regards to the collimator axis. It is recommended that users performing HPGe measurements of SNF should consider a large volume coaxial detector or position a large planar at a 90-degree angle.

\subsection{SUMMED SPECTRUM OF ROD 30AD05}

Below is a simple summation of the 700 spectra acquired along the length of rod 30AD05 using the PeakEasy Software program [12]. PeakEasy is useful for such simple spectra manipulations and as a firstorder evaluation of the peaks present.

Assembly 30A has average declared burnup of $52 \mathrm{GWd} / \mathrm{MTU}$ and had been discharged from the reactor core 6-7 years previously. It was expected that the spectra for 30AD05 would be dominated by the three long-lived fission products that emit gamma rays: ${ }^{134} \mathrm{Cs},{ }^{137} \mathrm{Cs}$, and ${ }^{154} \mathrm{Eu}$. The summed spectrum shown below in Figure 13 clearly shows these isotopes. The radiation-induced x-rays from uranium are also clearly visible.

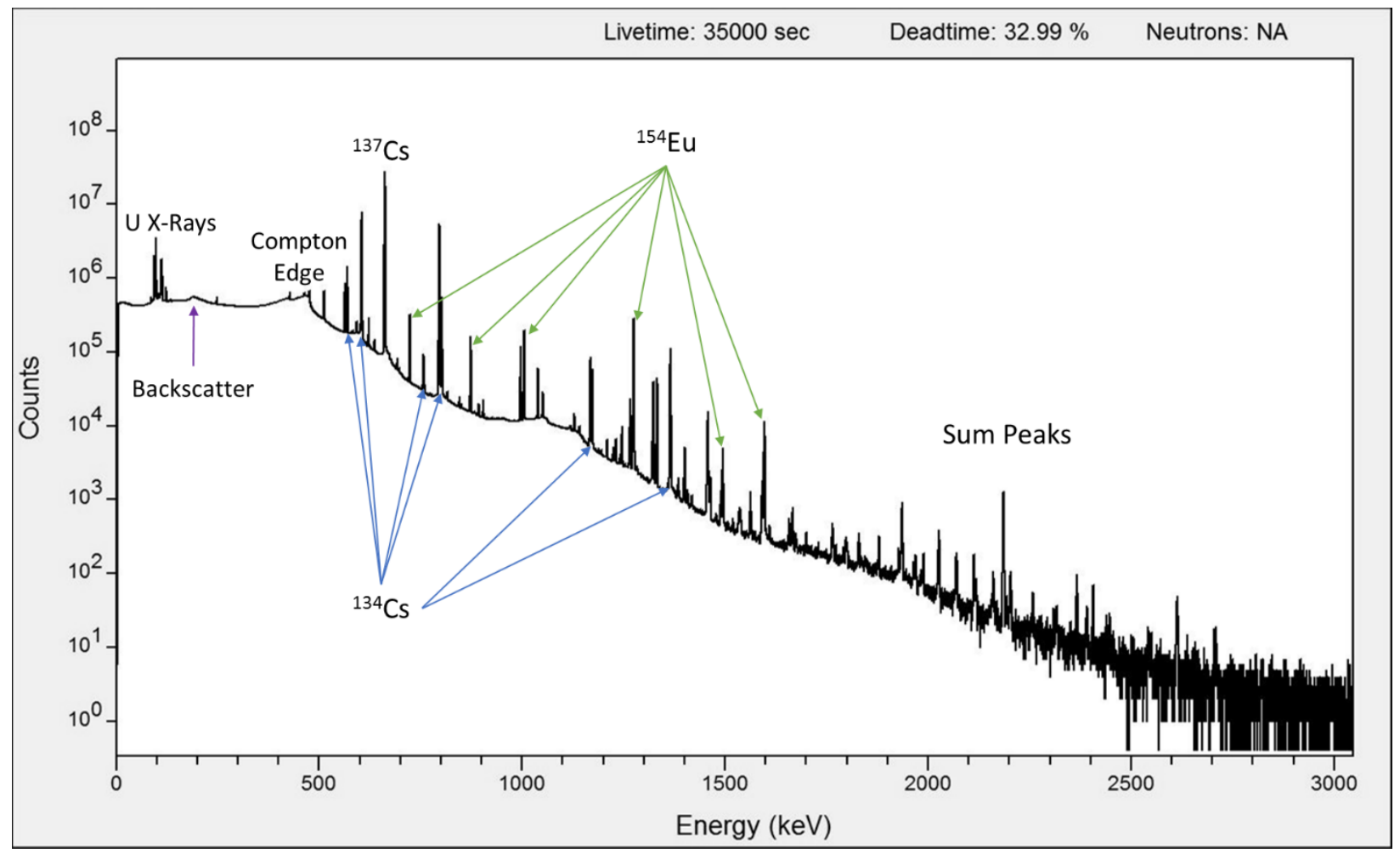

Figure 13. Sum spectrum of rod 30AD05. The spectrum shows the primary fission product gamma-ray peaks we would expect and the primary activation nuclide. Notice the $y$-axis is a log scale.

Above the 1,596 keV gamma ray from ${ }^{154} \mathrm{Eu}$, the spectrum is dominated by small peaks that are most likely from random coincidence summing. This makes sense because of the high-count rates. Note the deadtime estimate in the figure and the long count time of the summed spectrum.

\subsection{AXIAL SCAN DATA}

From the 700 spectra, individual deadtime corrected gross peak counts can be plotted against the position along the SNF rod where the data was acquired. Such locational data provides a visual representation of the differences in the burnup along the height of the rod and within the reactor. It is expected that the gross count rates will be approximately constant, within statistics, along most of the rod and drop on 
either end. In addition, there is a plenum on one side of the rod, from approximately 3,600-3,800 mm, where the emitted gamma radiation is dominated by ${ }^{60} \mathrm{Co}$ from the irradiation of the spring in the plenum.

Figure 14 shows the axial scan gross counts for a ROI around the $661.6 \mathrm{keV}$ peak from ${ }^{137} \mathrm{Cs}$ for rod 30AD05. The ROI extended from $658.2 \mathrm{keV}$ to $665.5 \mathrm{keV}$. Grid spacers between sections of fuel pellets are evident by dips in the gross count rates.

As part of the Sister Rods project, the gross count rate was acquired for three different ROIs using a 1 in. $\times 1$ in. $\mathrm{NaI}(\mathrm{Tl})$ detector. The collimator aperture was opened to $1 \mathrm{~mm}$ for these scans. Because of the size of the collimator, dips could be seen in the data corresponding to the transition between individual fuel pellets. Because the HPGe data was acquired with a much larger aperture opening, this granularity was not achieved.

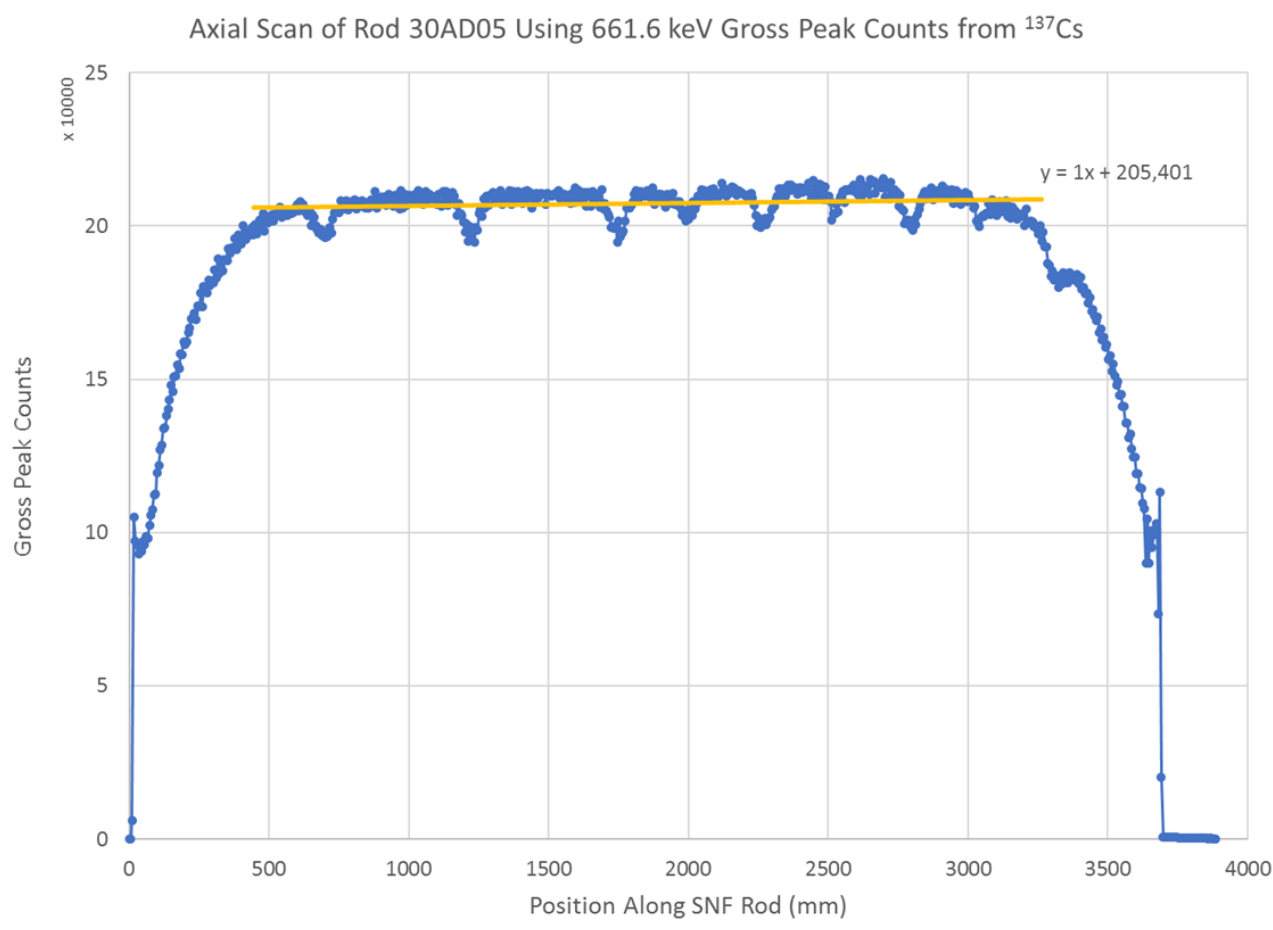

Figure 14. Axial scan of rod 30AD05 using the gross peak counts from the $661.6 \mathrm{keV}$ peak of ${ }^{137}$ Cs. The dips in the peak counts correspond to grid spacers between sections of fuel pellets.

We also looked at the axial scan of rod 3D8B02, which is shown in Figure 15. Note the axial scan data, in this case, showed a very strong linear trend with axial position in the high burnup regions of the rod. 


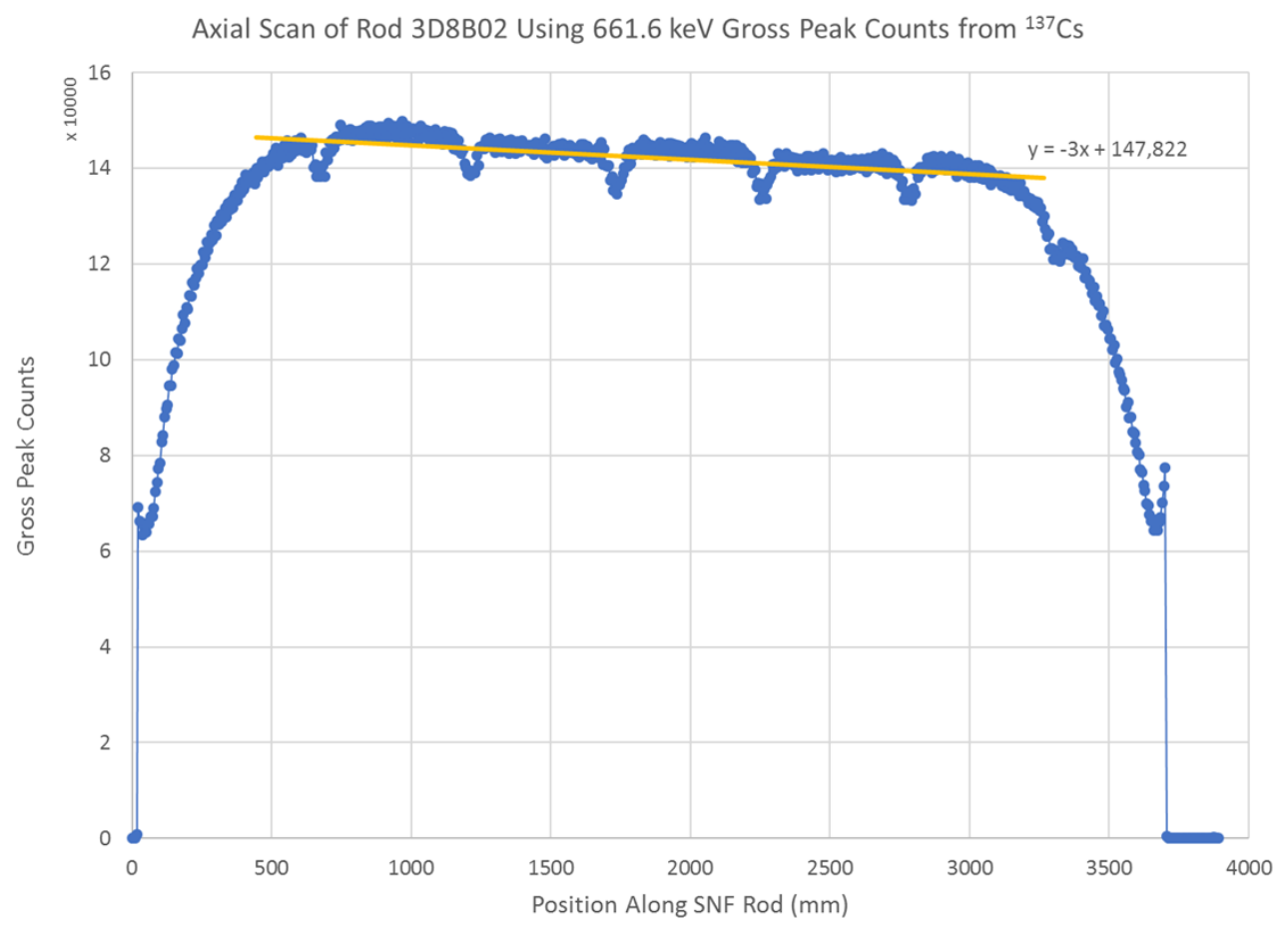

Figure 15. Axial scan of rod 3D8B02 using the gross peak counts from the $661.6 \mathrm{keV}$ peak of ${ }^{137} \mathbf{C s}$. There is a distinct linear trend of the peak counts with location along the rod.

Our expectation was that most of the SNF rod would have a ${ }^{137} \mathrm{Cs}$ gross count rate approximately constant, like that shown in Figure 14, so this notable trend was surprising. Further analysis was performed using the axial scan data of 3D8B02. The rod was divided into axial sections, as shown in Figure 16, and the spectra were summed over those sections. As a result, peak fitting could be performed on the peaks of interest and provide good statistics. Peak fitting analysis is impractical to perform on all 700 spectra because a majority of the individual peaks have poor statistics as a result of the relatively short count time, radionuclide concentration, and branching ratio.

The rod was divided into axial sections, as shown in Figure 16, and the spectra summed over those sections. As a result, peak fitting could be performed on the peaks of interest and provide us with good statistics. Peak fitting analysis is impractical to perform on all 700 spectra because a majority of the peaks would have poor statistics as a result of count time, radionuclide concentration, and branching ratio. 


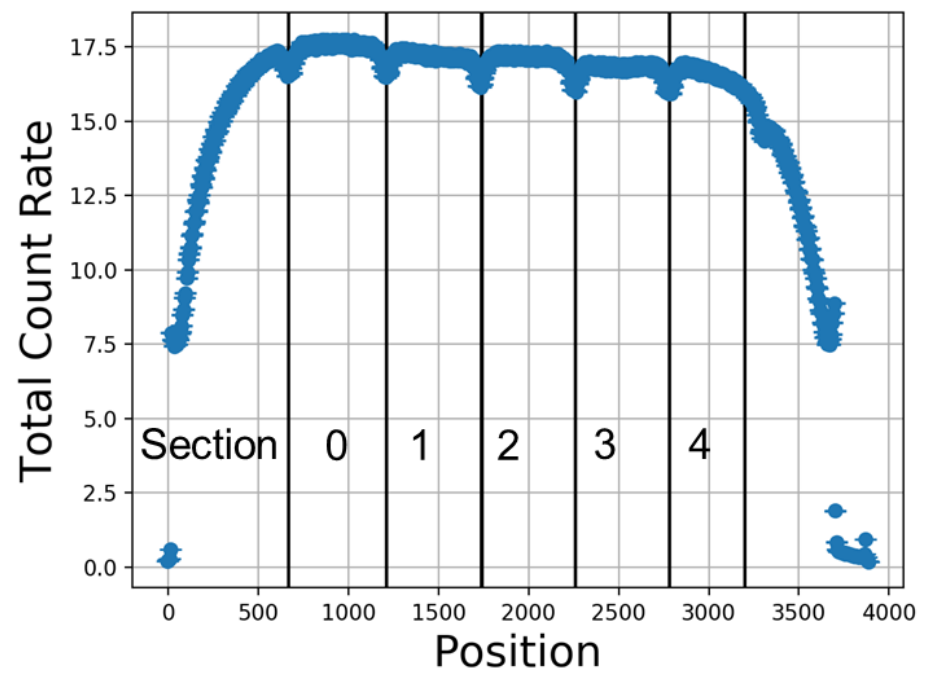

Figure 16. Illustration of the axial scan data divided into sections.

Using the section-based summed spectrum, the peaks of interest were fit by nonlinear least-squares. The net peak count rate for the ${ }^{137} \mathrm{Cs}$ peak at $662 \mathrm{keV}$ and the $1,274 \mathrm{keV}$ peak of ${ }^{154} \mathrm{Eu}$ are plotted by section in Figure 17. The count rate of the ${ }^{154} \mathrm{Eu}$ shows a trend opposite to the ${ }^{137} \mathrm{Cs}$.
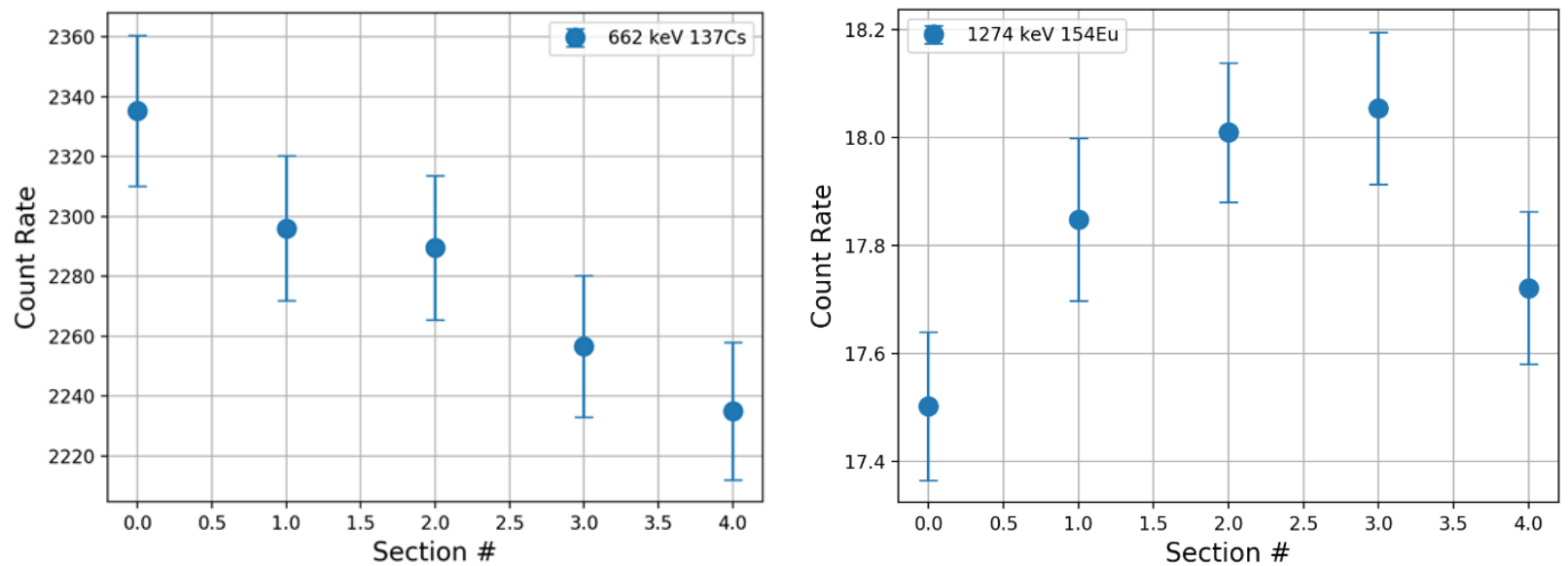

Figure 17. Net count rates of the $662 \mathrm{keV}$ peak of ${ }^{137} \mathrm{Cs}($ left $)$ and the $1,274 \mathrm{keV}$ peak of ${ }^{154} \mathrm{Eu}($ right $)$ as a function of rod section.

Subsequently, a relative efficiency calibration was calculated for the measurements of rod 3D8B02 by taking advantage of the numerous ${ }^{154} \mathrm{Eu}$ peaks visible in the spectra. From the nuclear data, net count rates, and the relative efficiency calibration, the number ratio for the ${ }^{154} \mathrm{Eu} \backslash{ }^{137} \mathrm{Cs}$ isotopic ratio were calculated by section. The number ratios, which are used in the calculation of burnup, were calculated by section and demonstrate the same trend as the ${ }^{154} \mathrm{Eu}$ net count rates shown in Figure 18. One could then speculate two reasons; the burnup across the rod was not consistent because of reactor conditions or fission products have migrated along the length of the fuel rod. The latter is less likely but possible. 


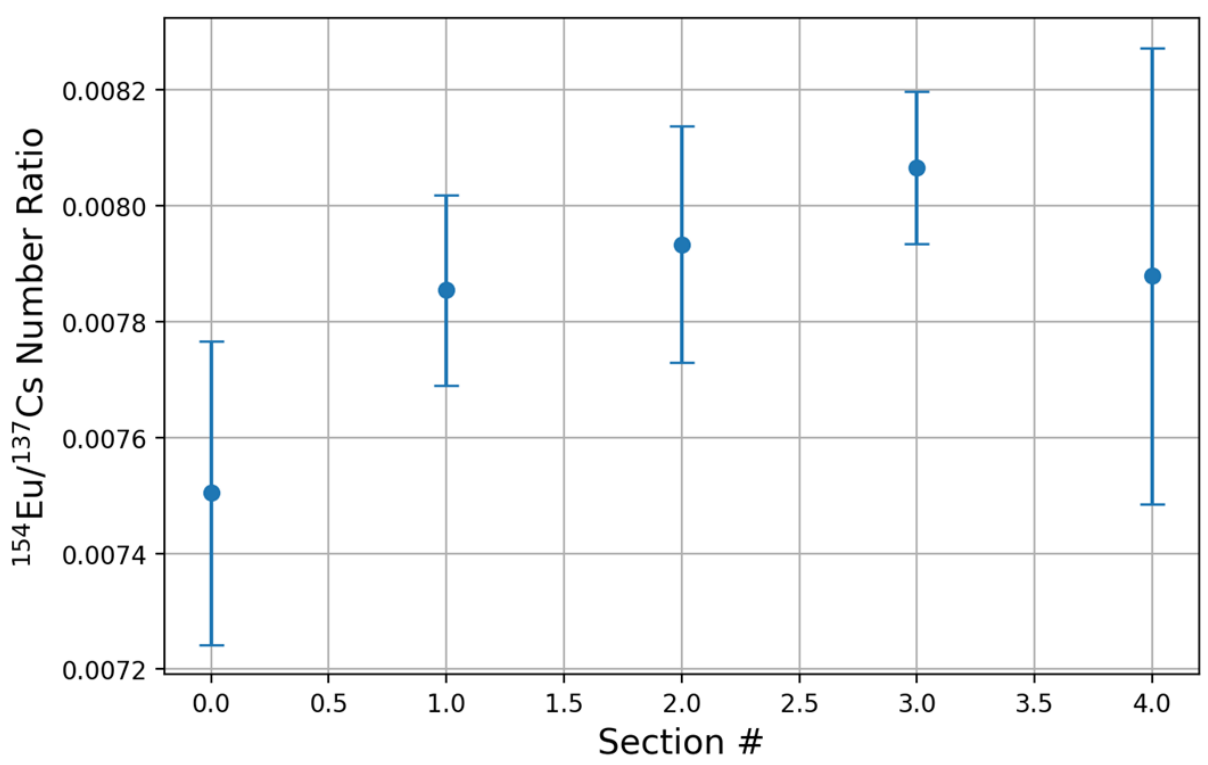

Figure 18. Number ratio for ${ }^{154} \mathrm{Eu} /{ }^{137} \mathrm{Cs}$ by section in rod 3D8B02.

\section{ACCESS TO SPECTRA}

A secured-access site has been set up to store all the gamma spectroscopy files, the multichannel analyzer input definition files, and photographs of the measurement setup. Other relevant documents will also be stored there. The URL is http://share.ornl.gov/sites/SR SNF GSpec/default.aspx.

To access the site, one must register for an XCAMS account. To request an account, go to https://xcams.ornl.gov and fill out the form. Upon successful completion, please email Susan Smith at smithsk@ornl.gov to request access to the site.

\section{REFERENCES}

1. Willman, C., Håkansson, A., Osifo, O., Bäcklin, A., and Svärd, S. J. (2006). "Nondestructive assay of spent nuclear fuel with gamma-ray spectroscopy," Annals of Nuclear Energy, Volume 33, Issue 5, pg. 427-38.

2. Willman, C., Håkansson, A., Osifo, O., Bäcklin, A., and Svärd, S. J. (2006). "A nondestructive method for discriminating MOX fuel from LEU fuel for safeguards purposes," Annals of Nuclear Energy, Volume 33, Issue 9, pg. 766-73.

3. Favalli, A., Vo, D., Grogan, B., Jansson, P., Liljenfeldt, H., Mozin, V., Schwalbach, P., Sjöland, A., Tobin, S. J., Trellue, H., and Vaccaro, S. (2016). "Determining initial enrichment, burnup, and cooling time of pressurized-water-reactor spent fuel assemblies by analyzing passive gamma spectra measured at the Clab interim-fuel storage facility in Sweden," Nuclear Instruments \& Methods in Physics Research. Section A, Accelerators, Spectrometers, Detectors and Associated Equipment, Volume 820, pg. 102-111.

4. Vo, D., Favalli, A., Grogan, B., Jansson, P., Liljenfeldt, H., Mozin, V., Schwalbach, P., Sjöland, A., Tobin, S. J., Trellue, H., and Vaccaro, S. (2016). "Passive gamma analysis of boiling-water-reactor 
assemblies," Nuclear Instruments and Methods in Physics Research, Section A: Accelerators, Spectrometers, Detectors and Associated Equipment, Volume 830, pg. 325-37.

5. Vaccaro, S., Tobin, S. J., Favalli, A., Grogan, B., Jansson, P., Liljenfeldt, H., Mozin, V., Hu, J., Schwalbach, P., Sjöland, A., Trellue, H., and Vo, D. (2016). "PWR and BWR spent fuel assembly gamma spectra measurements," Nuclear Instruments and Methods in Physics Research, Section A: Accelerators, Spectrometers, Detectors and Associated Equipment, Volume 833, pg. 208-225.

6. Koleška, M., Viererbl, L., Marek, M., Ernest, J., Šunka, M., and Vinš, M. (2016). "Determination of IRT-2M fuel burnup by gamma spectrometry," Applied Radiation and Isotopes, Volume 107, pg. 92 97.

7. B. D. Hanson, S. C. Marschman, M. C. Billone, J. Scaglione, K. B. Sorenson, and S. J. Saltzstein. (2016). High Burnup Spent Fuel Data Project Sister Rod Test Plan Overview. FCRD-UFD-2016000063. PNNL-25374. Available: https://www.energy.gov/sites/prod/files/2017/02/f34 /2HBUSNFSisterRodTestPlanOverview.pdf.

8. Scaglione, J. M., Montgomery, R., and Bevard, B. B. (2016). Post Irradiation Examination Plan for High-Burnup Demonstration Project Sister Rods. FCRD-UFD-2016-000422. ORNL/SR-2016/111. Oak Ridge National Laboratory, Oak Ridge, TN. doi: 10.2172/1248793.

9. Montgomery, R., and Bevard, B. B. (2017). Revised Draft: Post Irradiation Examination Plan for High-Burnup Demonstration Project Sister Rods. Oak Ridge National Laboratory, Oak Ridge, TN.

10. Irradiated Fuels Examination Laboratory Building 3525: Facility Self-Study Guide, Rev. 1, Oak Ridge National Laboratory, Oak Ridge, TN, September 21, 2010.

11. Montgomery, R., Bevard, B., Morris, R. N., Goddard Jr., J., Smith, S. K., Hu, J., Beale, J., and Yoon, B. (2017). Sister Rod Nondestructive Examination Annual Report FY 2017. SFWD-SFWST-2017000003. ORNL/SPR-2017/484. Oak Ridge National Laboratory, Oak Ridge, TN.

12. DeCooman, W. J., and Spellman, D. J., (2007). "Nuclear fuel post-irradiation examination equipment package," Waste Management Symposium 2007, Tucson, AZ, February 25-March 1.

13. Balraj, S. and Chen, J. (2014). "Nuclear data sheet for A = 85." Nuclear Data Sheets, Volume 116, Number 1. doi: 10.1016/j.nds.2014.01.001.

14. Rooney, B., Garner, S., Felsher, P., and Karpius, P. (2015). PeakEasy 4.91 [Computer Program], Los Alamos National Laboratory, Los Alamos, NM, Release LA-CC-13-040. Available: https://PeakEasy.lanl.gov.

15. Reilly, D., N. Ensslin, H. Jr. Smith, and S. Kreiner. (1991). "Passive Nondestructive Assay of Nuclear Materials.”NUREG/CR-5550. LA-US-90-732. 